\title{
Metal-Organic Framework-101 (MIL-101): Synthesis, Kinetics, Thermodynamics, and Equilibrium Isotherms of Remazol Deep Black RGB Adsorption
}

\author{
Vo Thi Thanh Chau, ${ }^{1}$ Huynh Thi MinhThanh, ${ }^{2}$ Pham Dinh Du, ${ }^{3}$ Tran Thanh Tam Toan, ${ }^{4}$ \\ Tran Ngoc Tuyen, ${ }^{4}$ Tran Xuan Mau $\left(10,{ }^{4}\right.$ and Dinh Quang Khieu $\mathbb{1}^{4}$ \\ ${ }^{1}$ Tran Quoc Tuan High School, Quảng Ngãi 570000, Vietnam \\ ${ }^{2}$ Department of Chemistry, Qui Nhon University, Binh Định 590000, Vietnam \\ ${ }^{3}$ Faculty of Natural Sciences, Thu Dau Mot University, Thủ Dâu Một 820000, Vietnam \\ ${ }^{4}$ University of Sciences, Hue University, Hue 530000, Vietnam \\ Correspondence should be addressed to Dinh Quang Khieu; dqkhieu@hueuni.edu.vn
}

Received 7 January 2018; Revised 11 April 2018; Accepted 14 May 2018; Published 24 June 2018

Academic Editor: Hossein Kazemian

Copyright @ $\odot 2018$ Vo Thi Thanh Chau et al. This is an open access article distributed under the Creative Commons Attribution License, which permits unrestricted use, distribution, and reproduction in any medium, provided the original work is properly cited.

In the present paper, the synthesis of metal-organic framework-101 (MIL-101) and Remazol Deep Black RGB (RDB) adsorption on MIL-101 were demonstrated. The kinetics of RDB adsorption on MIL-101 was studied using Weber's intraparticle diffusion model and the pseudo-first- and pseudo-second-order kinetic models. Particularly, the statistical method of piecewise linear regression and multinonlinear regression was employed to analyse the adsorption data according to the previously mentioned kinetic models. The results indicated that the adsorption process followed the three-step pseudo-first-order kinetic equation, which was consistent with the results of the intraparticle diffusion model with three linear segments. This model best described the experimental data. In addition, the adsorption isotherm data were studied using five adsorption models, namely, Langmuir, Freundlich, Redlich-Peterson, Toth, and Sips in nonlinear forms, and the Langmuir model is the most appropriate for the experimental data. The values of energies of activation of adsorption were calculated, and they revealed that the adsorption process was of endothermic chemical nature. A statistical comparison using Akaike information criterion to estimate the goodness of fit of the kinetic and isotherm models was presented.

\section{Introduction}

It is well known that wastewater from textile industries, pulp mills, and dyestuff manufacturing has been a potential threat to environment $[1,2]$. Various treatment processes such as physical separation, chemical oxidation, and biological degradation have been widely investigated to remove dyes from wastewaters [3]. Among these processes, adsorption technology is considered as one of the most competitive methods because it does not require high operating temperature and has a simple operation as well as low cost, and several coloring materials can be removed simultaneously [4].

MIL-101 has demonstrated good performance in storage and adsorption of gas such as hydrogen storage [5], adsorption of $\mathrm{CO}_{2}$ and $\mathrm{CH}_{4}$ [6], and long-chain alkanes [7]. However, there are very few reports studying the adsorption of dyes from aqueous solutions [8-10]. MOFs in general and MIL-101 in particular exhibit high efficiency for adsorption of dyes from aqueous solutions due to their unique structures such as large surface areas, ordered porosity, and high density of adsorption sites (anion and cation). MIL-101 demonstrates excellent adsorption properties for dyes, such as methyl orange (MO), xylenol orange (XO), and uranine. For expanding applications of MIL-101, studying the adsorption of this material for Remazol Deep Black RGB (denoted as RDB) used widely in dye industry will be a concern of this work.

Azo dyes with an azo group are widely used in many textile industries due to their low cost, high solubility, and stability. These dyes and their intermediate products are toxic, carcinogenic, and mutagenic to aquatic life. Remazol Deep Black RGB is a common diazo reactive dye, widely used in textile industries [11]. It is stable and hard to degrade biologically due 


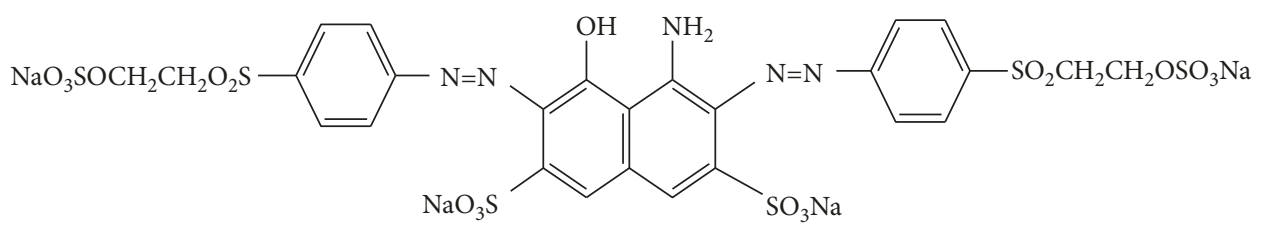

SCHeme 1: Molecular structure of RDB.

to the presence of aromatic rings. Thus, $\mathrm{RDB}$ removal from textile wastewater has drawn much attention among researchers. Several techniques including adsorption, electrochemistry, and biosorption for RDB treatment have been reported. Soloman et al. [11] applied the electrochemical treatment to hydrolyze Remazol Black. They demonstrated that the performance of the batch recirculation system was better than other reactor configurations studied in terms of capacity utilization and energy consumption. Brazilian pine-fruit shells (Araucaria angustifolia) in their natural form were used as an adsorbent for the removal of RDB dye from aqueous effluents [12]. A biosorption process to discard azo dyes by fungi (Aspergillus flavus) was investigated in batch reactors [13]. Ninety percent of the dye in a $100 \mathrm{mg} / \mathrm{L}$ solution was removed. Recently, Thanh et al. [14] reported that iron doping to ZIF-8 significantly enhances RDB adsorption capacity. Fe-ZIF-8 also exhibits photocatalytic degradation of RDB under visible light [15].

Batch adsorption studies focus on two main trends: (i) designing and optimizing experiments with the evaluation of the influence of the experimental variables-this approach enables to estimate the magnitude of the influence of the factors affecting the process and their interactions [16] — and (ii) kinetics, thermodynamics, and equilibrium isotherm adsorption studies $[14,17]$. For the latter, several models are used to study adsorption kinetics and isotherms. The parameters in these models are calculated with linear or nonlinear regression approaches. However, the number of parameters in each mode is different. For example, the Langmuir isotherm model contains two parameters, while the Redlich-Peterson isotherm model has three parameters. It is obvious that the greater the number of model parameters, the lower the relative errors (REs) or the sum of squared errors (SSEs). Therefore, the model compatibility needs to be evaluated including SSEs or REs and the number of model parameters as well as the experimental points. However, in the majority of current publications, the goodness of fit for models is estimated based on only the REs or SSEs. To the best of our knowledge, the research on this issue is limited.

In the present study, MIL-101 was employed as an adsorbent for removing RDB dye. The effects of initial concentration, adsorbent particle size, agitation speed, temperature, and $\mathrm{pH}$ on the adsorption behavior of RDB onto MIL-101 were investigated. The adsorption kinetic and isothermal studies and the goodness of fit for models were addressed.

\section{Experimental}

2.1. Materials. Chromium (III) nitrate nonahydrates $\left(\mathrm{Cr}\left(\mathrm{NO}_{3}\right)_{3} \cdot 9 \mathrm{H}_{2} \mathrm{O}\right.$, Merck, Germany), terephthalic acid, $\left(\mathrm{C}_{6} \mathrm{H}_{4}(\mathrm{COOH})_{2}\right.$, Merck, Germany) $\left(\mathrm{H}_{2} \mathrm{BDC}\right)$, and hydrofluoric acid (HF, 40\%, Merck, Germany) were utilized in this study. Remazol Deep Black RGB $\left(\mathrm{C}_{26} \mathrm{H}_{21} \mathrm{~N}_{5} \mathrm{Na}_{4} \mathrm{O}_{19} \mathrm{~S}_{6}\right.$ ), (molecular weight $=991.82$ ) was supplied by Thuy Duong Textile Company, Vietnam. The molecular structure of RDB is shown in Scheme 1.

2.2. Apparatus. The powder X-ray diffraction (XRD) pattern was recorded by means of a D8 Advance (Bruker, Germany) with $\mathrm{CuK} \alpha$ radiation $(\lambda=1.5406 \AA)$. The morphology of the obtained samples was determined using transmission electron microscope (TEM) on JEOL JEM-2100F. The specific surface area of the samples was determined by means of nitrogen adsorption/desorption isotherms using a Micromeritics 2020 volumetric adsorption analyzer system. Visible spectrophotometry was measured by using Lambda 25 Spectrophotometer (PerkinElmer, Singapore) at $\lambda_{\max }$ of RDB dye $(600 \mathrm{~nm})$.

2.3. Preparation of MIL-101. MIL-101 was synthesized from chromium (III) nitrate nonahydrates, $\mathrm{H}_{2} \mathrm{BDC}$, and $\mathrm{HF}$ using the hydrothermal method [18]. Three samples of MIL-101 with different molar ratios of $\mathrm{HF} / \mathrm{H}_{2} \mathrm{BDC}=0.00,0.25$, and 0.75 were prepared. In a typical procedure, a mixture of $10 \mathrm{mmol}$ of $\mathrm{H}_{2} \mathrm{BDC}, 12.5 \mathrm{mmol}$ of $\mathrm{Cr}\left(\mathrm{NO}_{3}\right)_{3} \cdot 9 \mathrm{H}_{2} \mathrm{O}, x \mathrm{mmol}$ of HF ( $x=0.00,0.25$, and 0.75$)$, and $350 \mathrm{mmol}$ of $\mathrm{H}_{2} \mathrm{O}$ was heated in a Teflon-lined stainless steel autoclave at $200^{\circ} \mathrm{C}$ for $8 \mathrm{~h}$. The resulting green solid was filtered and then washed with ethanol in a Soxhlet apparatus for around $12 \mathrm{~h}$ to completely remove the unreacted amount of $\mathrm{H}_{2} \mathrm{BDC}$. The obtained MIL-101 was denoted as MHF0 for the molar ratio of $\mathrm{HF} / \mathrm{H}_{2} \mathrm{BDC}=0, \mathrm{MHF} 0.25$ for 0.25 , and MHF0.75 for 0.75 .

2.4. Adsorption Kinetic and Thermodynamic Studies. Kinetic studies were carried out in a $3 \mathrm{~L}$ plastic beaker. This beaker was equipped with a stainless steel flat-blade impeller using an electric motor to stir the dye solution and a tap near the bottom to withdraw the liquid at any time. MIL-101 (0.50 g) was mixed thoroughly with $1000 \mathrm{~mL}$ of the dye solution in the beaker at room temperature. $10 \mathrm{~mL}$ of the mixture was withdrawn periodically, and MIL-101 was removed by using a centrifuge. The final dye concentration was determined using the spectrophotometric method. The adsorption capacity of the adsorbent was calculated according to the following formula:

$$
q_{t}=\frac{V\left(C_{0}-C_{t}\right)}{m},
$$

where $q_{t}$ is the adsorption capacity $\left(\mathrm{mg}^{-g^{-1}}\right)$ at $t$ time, $C_{0}$ is the initial dye concentration $\left(\mathrm{mg} \cdot \mathrm{L}^{-1}\right), C_{t}$ is the dye 
concentration $\left(\mathrm{mg} \cdot \mathrm{L}^{-1}\right)$ at time $t, V$ is the volume of dye solution (L), and $m$ is the mass of the adsorbent (g).

For the adsorption isotherm study, an amount of 30, 40, $50,60,70,80,90$, and $110 \mathrm{mg}$ of MIL-101 was added to 8 stopper $250 \mathrm{~mL}$ Erlenmeyer flasks containing $100 \mathrm{~mL}$ of $100 \mathrm{mg} / \mathrm{L} \mathrm{RDB}$ solution. The flasks were then placed into a shaker bath at $28 \pm 1^{\circ} \mathrm{C}$ for 24 hours. Thereafter, the supernatant liquid was separated by centrifugation and the final dye concentration was determined with the method mentioned above.

In order to study formal and diffusion kinetics, Weber's intraparticle diffusion model and pseudo-first- and pseudosecond-order kinetic models were used. Weber's intraparticle diffusion model is described as in the following equation [19]:

$$
q_{t}=k_{i} \cdot t^{1 / 2}+I
$$

where $k_{i}$ is intraparticle diffusion rate constant $\left(\mathrm{mg} \cdot \mathrm{g}^{-1} \cdot \mathrm{min}^{-0.5}\right)$ and $I$ is the intercept which represents the thickness of the boundary layer.

If intraparticle diffusion is the rate-limiting step, then the plot of $q$ versus $t^{0.5}$ will give a straight line with a slope that equals $k_{i}$ and an intercept equal to zero.

The pseudo-first- and pseudo-second-order kinetic models in the nonlinear form are expressed as follows [20]:

$$
\begin{aligned}
& q_{t}=q_{\mathrm{e}} \cdot\left(1-e^{-k_{1} \cdot t}\right), \\
& q_{t}=q_{\mathrm{e}} \cdot \frac{q_{\mathrm{e}} \cdot k_{2} \cdot t}{1+q_{\mathrm{e}} \cdot k_{2} \cdot t},
\end{aligned}
$$

where $q_{t}$ and $q_{\mathrm{e}}$ are the adsorption capacity at time $t$ (min) and at equilibrium time, respectively, $k_{1}$ is the rate constants of the pseudo-first-order model $\left(\mathrm{min}^{-1}\right)$, and $k_{2}$ is the rate constant of the pseudo-second-order kinetic model $\left(\mathrm{g} \cdot \mathrm{mg}^{-1} \cdot \mathrm{min}^{-1}\right)$.

For the thermodynamic study, the experiments were conducted in the same way as in the adsorption kinetics study. However, the adsorption temperature was fixed at $298,308,318$, and $328 \mathrm{~K}$. The activation energy, $E_{\mathrm{a}}$, was determined using the Arrhenius equation [21]:

$$
k=A \cdot e^{-\left(E_{\mathrm{a}} / R \cdot T\right)},
$$

where $k$ is the rate constant, $A$ is the frequency factor, $R$ is the gas constant $\left(8.314 \mathrm{~J} \mathrm{~mol}^{-1} \cdot \mathrm{K}^{-1}\right)$, and $T$ is the absolute temperature in Kelvin. Taking the natural logarithm of both sides of (4), one obtains

$$
\ln k=-\frac{E_{\mathrm{a}}}{R \cdot T}+\ln A .
$$

By linearly plotting $\ln k$ versus $1 / T$, one could obtain $E_{\mathrm{a}}$ from the slope $\left(-E_{\mathrm{a}} / R\right)$.

In order to evaluate whether the adsorption process is spontaneous, the adsorption thermodynamic parameters are needed. The standard Gibbs free energy of adsorption $\left(\Delta G^{0}\right)$ is given by the following expression:

$$
\Delta G^{0}=\Delta H^{0}-T \Delta S^{0},
$$

where $\Delta G^{0}, \Delta H^{0}$, and $\Delta S^{0}$ are the change of standard Gibbs energy, enthalpy, and entropy, respectively.
$\Delta G^{0}$ is given by the van't Hoff equation:

$$
\Delta G^{0}=-R \cdot T \cdot \ln K_{\mathrm{d}},
$$

where $K_{\mathrm{d}}$ is the distribution coefficient of the solute ions and equal to $q_{\mathrm{e}} / C_{\mathrm{e}}[22,23]$ and the others are described earlier.

By replacing (6) to (7), one obtains

$$
\ln K_{\mathrm{d}}=-\frac{\Delta H^{0}}{R \cdot T}+\frac{\Delta S^{0}}{R} \text {. }
$$

The value of $\Delta H^{0}$ and $\Delta S^{0}$ is calculated from the slope and intercept of the linear plot of $\ln K_{\mathrm{d}}$ versus $1 / T$.

2.5. Adsorption Isotherm Study. Experimental data were analysed according to five isotherm models by Langmuir, Freundlich, Redlich-Peterson, Sips, and Toth.

Langmuir isotherm: Langmuir model is valid for monolayer sorption onto the surface. It could be expressed as follows [24]:

$$
q_{\mathrm{e}}=q_{\mathrm{m}} \cdot \frac{K_{\mathrm{L}} \cdot C_{\mathrm{e}}}{1+K_{\mathrm{L}} \cdot C_{\mathrm{e}}},
$$

where $q_{\mathrm{m}}$ is the maximum monolayer capacity amount $\left(\mathrm{mg} \cdot \mathrm{g}^{-1}\right), K_{\mathrm{L}}$ is the equilibrium constant, $q_{\mathrm{e}}$ is the equilibrium adsorption capacity $\left(\mathrm{mg} \cdot \mathrm{g}^{-1}\right)$, and $C_{\mathrm{e}}$ is the equilibrium concentration of adsorbate $\left(\mathrm{mg} \cdot \mathrm{L}^{-1}\right)$.

Freundlich isotherm: The Freundlich equation is an empirical relation based on the sorption onto a heterogeneous surface. It is commonly represented as [25]

$$
q_{\mathrm{e}}=K_{\mathrm{F}} \cdot C_{\mathrm{e}}^{1 / n},
$$

where $K_{\mathrm{F}}\left(\left(\mathrm{mg} \cdot \mathrm{g}^{-1}\right) \cdot\left(\mathrm{mg} \cdot \mathrm{L}^{-1}\right)^{n}\right)$ and $n$ are the Freundlich parameters related to adsorption capacity and adsorption intensity, respectively.

The maximum capacity, $q_{\mathrm{m}}\left(\mathrm{mg} \cdot \mathrm{g}^{-1}\right)$, can be calculated from the following equation [26]:

$$
q_{\mathrm{m}}=K_{\mathrm{F}} \cdot C_{0}^{1 / n},
$$

where $C_{0}$ is the initial concentration.

Redlich-Peterson isotherm: Redlich-Peterson isotherm [27] contains three parameters and involves the features of both Langmuir and Freundlich isotherms. It can be described as follows:

$$
q_{\mathrm{e}}=\frac{K_{\mathrm{R}} \cdot C_{\mathrm{e}}}{1+a_{\mathrm{R}} \cdot C_{\mathrm{e}}^{b_{\mathrm{R}}}},
$$

where $K_{\mathrm{R}}\left(\mathrm{L} \cdot \mathrm{g}^{-1}\right)$ and $a_{\mathrm{R}}\left(\mathrm{L} \cdot \mathrm{mg}^{-1}\right)$ are the Redlich-Peterson isotherm constants and $b_{\mathrm{R}}$ is the exponent which lies between 0 and 1 .

When $b_{\mathrm{R}}$ approaches $1,(12)$ becomes the Langmuir equation. Then, the maximum adsorption capacity, $q_{\mathrm{m}}$ $\left(\mathrm{mg} \cdot \mathrm{g}^{-1}\right)$, can be determined by the following equation:

$$
q_{\mathrm{m}}=\frac{K_{\mathrm{R}}}{a_{\mathrm{R}}} .
$$

Sips isotherm: Sips isotherm is a combination of the Langmuir and Freundlich isotherms and expected to describe heterogeneous surfaces much better [24]. The model can be written as [28] 


$$
q_{\mathrm{e}}=\frac{K_{\mathrm{s}} \cdot C_{\mathrm{e}}^{1 / n}}{1+a_{\mathrm{s}} \cdot C_{\mathrm{e}}^{1 / n}},
$$

where $K_{\mathrm{s}}$ and $a_{\mathrm{s}}$ are the Sips constants related to the energy of adsorption. The maximum monolayer adsorption capacity could is given by $K_{\mathrm{a}} / a_{\mathrm{s}}$.

Toth isotherm: Toth isotherm is the Langmuir-based isotherm and considers a continuous distribution of site affinities. It is expressed as [29]

$$
q_{\mathrm{e}}=\frac{q_{\mathrm{m}} \cdot C_{\mathrm{e}}}{\left(K_{\mathrm{T}_{0}}+C_{\mathrm{e}}^{n}\right)^{1 / n}},
$$

where $K_{\mathrm{T}_{0}}$ is the Toth model constant and $n$ is the Toth model exponent $(0<n \leq 1)$. It is obvious that, for $n=1$, this isotherm reduces to the Langmuir equation.

2.6. Piecewise Linear Regression and Model Comparison. The application of Weber's model often suffers from uncertainties caused by the multilinear nature of its plots. Malash and El-Khaiary [30] proposed the piecewise linear regression for the analysis of multilinearity in intraparticle diffusion and film diffusion. In this method, the experimental data could be fixed for one-, two-, three-, or fourlinear-segment lines:

one-linear-segment line: $Y=B+A \cdot X$ (two parameters), two-linear-segment line: $Y=B+A \cdot X+C \cdot(X-D)$. SIGN $(X-D)$ (four parameters),

three-linear-segment line: $Y=B+A \cdot X+C \cdot(X-D)$. SIGN $\quad(X-D)+E \cdot(X-F) \cdot$ SIGN $\quad(X-F) \quad($ six parameters),

four-linear-segment line: $Y=B+A \cdot X+C \cdot(X-D)$. SIGN $(X-D)+E \cdot(X-F) \cdot$ SIGN $(X-F)+G \cdot(X-H)$. SIGN $(X-H)$ (eight parameters),

where the values of $A, B, C, D, E, F, G$, and $H$ are estimated by nonlinear regression. $D, F$, and $H$, called breakpoints, are the boundaries between the segments. The Microsoft Excel "SIGN" function is defined as follows:

$$
\operatorname{SIGN}(X-a)=\left(\begin{array}{cc}
1 & \text { if } X>a \\
0 & \text { if } X=a \\
-1 & \text { if } X<a
\end{array}\right) \text {. }
$$

The example for the three-linear-segment equation is expressed as follows:

$$
Y=\left(\begin{array}{ll}
A+C \cdot D+E \cdot F+X \cdot(B-C-E) & \text { if } X<D \\
A+E \cdot F+X \cdot(B-E) & \text { if } X=D \\
A-C \cdot D+E \cdot F+X \cdot(B+C-E) & \text { if } D<X<F \\
A-C \cdot D+X \cdot(B+C) & \text { if } X=F \\
A-C \cdot D-E \cdot F+X \cdot(B+C+E) & \text { if } X>F
\end{array}\right) .
$$

Then, the linear equation of the first segment is $y=a_{1} \cdot x+b_{1}$, where $b_{1}=B-C-E$ and $a_{1}=A+C \cdot D$ $+E \cdot F$. The linear equation of the second segment is

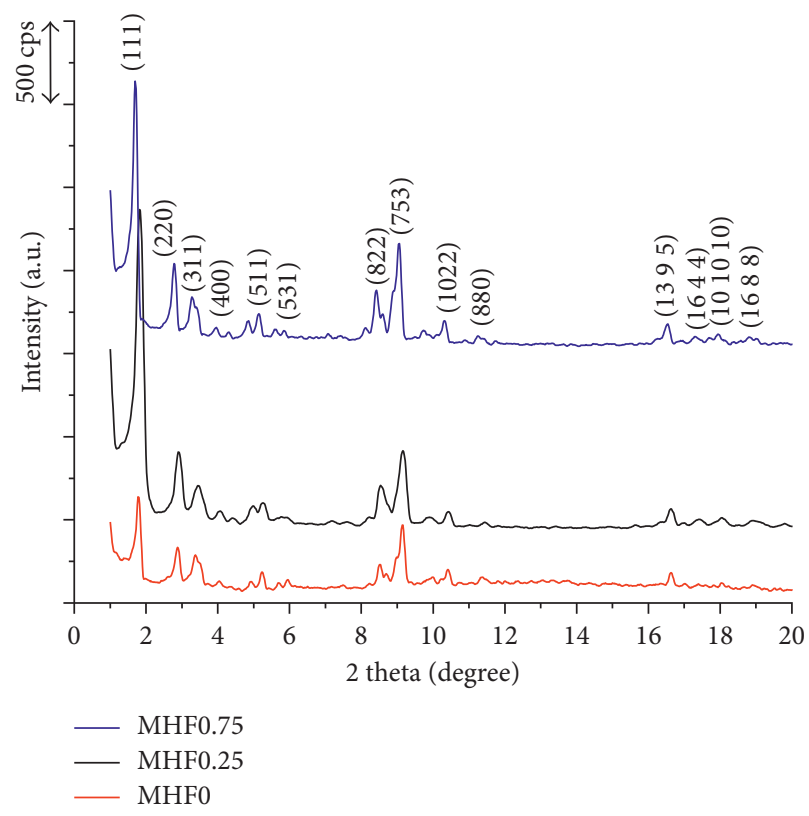

FIGURE 1: XRD patterns of MIL-101 synthesized with different molar ratios of $\mathrm{HF} / \mathrm{H}_{2} \mathrm{BDC}$.

$y=b_{2} \cdot x+a_{2}$, where $b_{2}=B+C-E$ and $a_{2}=A+C \cdot D+E \cdot F$. The linear equation of the third segment is $y=b_{3} \cdot x+a_{3}$, where $b_{3}=B+C+E$ and $a_{3}=A-C \cdot D-E \cdot F$.

The model's parameters are determined using the least squares method. This is calculated by minimizing the sum of squared errors, $\mathrm{SSE}_{\mathrm{S}}$, by numerical optimization techniques using the Solver function in Microsoft Excel. The function for minimization is

$$
\operatorname{SSE}_{S}=\sum_{1}^{N}\left(y_{\exp }-y_{\text {est }}\right)^{2},
$$

where $y_{\exp }$ is experimental datum and $y_{\text {est }}$ is the value estimated from the model.

The determination coefficient, $R^{2}$, is obtained by the following expression:

$$
R^{2}=\frac{1-\mathrm{SSE}_{S}}{\mathrm{SSE}_{T}},
$$

where $\mathrm{SSE}_{T}$ is the total sum of squares equal to $\sum_{1}^{N}\left(y_{\exp }-y_{\text {mean }}\right)^{2}\left(y_{\text {mean }}\right.$ is the mean value of $\left.y\right)$.

We know that increasing the number of linear segments increases the number of regression parameters that almost universally led to the decrease of SSEs or the increase of $R^{2}$. Therefore, the model compatibility cannot be based only on SSE or $R^{2}$ but must also include the number of regression parameters as well as the experimental points. Akaike's information criterion (AIC) is one of the well-known statistical methods used in this case.

$$
\mathrm{AIC}_{C}=N \cdot \ln \frac{\mathrm{SSE}}{N}+2 \cdot N_{\mathrm{p}}+\frac{2 \cdot N_{\mathrm{p}} \cdot\left(N_{\mathrm{p}}+1\right)}{N-N_{\mathrm{p}}-1},
$$

where $N_{\mathrm{p}}$ is the parameter of the model. The other parameters are described above. 


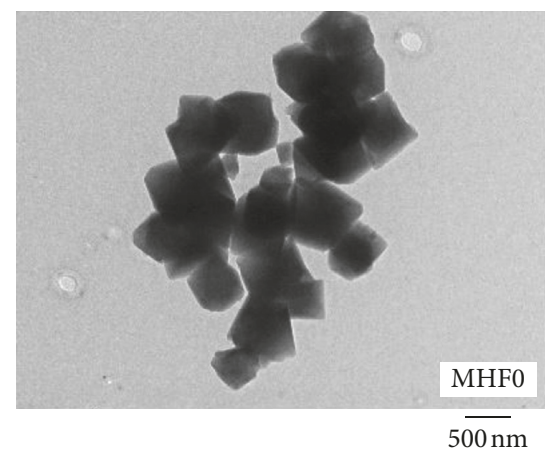

(a)

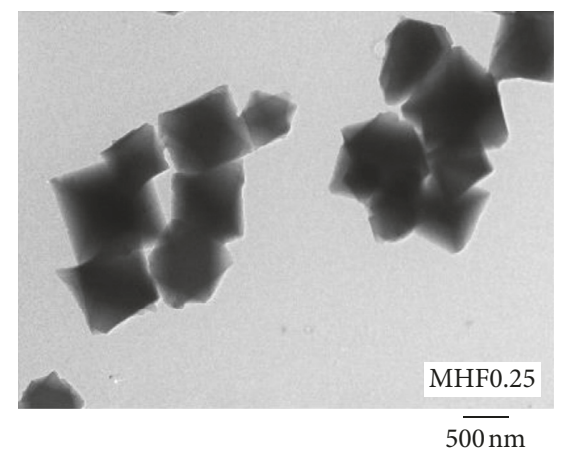

(b)

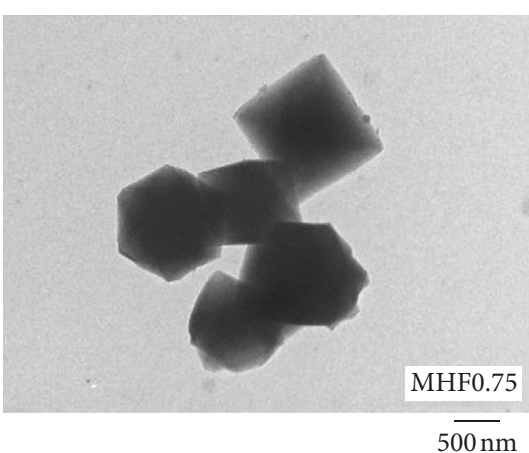

(c)

Figure 2: TEM images of MIL-101 synthesized with different molar ratios of $\mathrm{HF} / \mathrm{H}_{2} \mathrm{BDC}$.

The $\mathrm{AIC}_{C}$ is applied as $N$ is small compared with $N_{\mathrm{p}}$. $\mathrm{AIC}_{C}$ is only computed as $N$ is at least two units greater than $N_{\mathrm{p}}$. The value of $\mathrm{AIC}_{C}$ could be positive or negative, and the lower the $\mathrm{AIC}_{C}$ value, the better it is. Another way of comparing $\mathrm{AIC}_{C}$ is using the evidence ratio (ER) which is expressed as follows [17]:

$$
\mathrm{ER}=\frac{1}{e^{-0.5 \cdot \Delta}}
$$

where $\Delta$ is the absolute value of the difference between $\mathrm{AIC}_{C}$ and $\mathrm{AIC}_{S}$ scores. ER means that the model with lower AIC is $1 / e^{-0.5 \Delta}$ times more likely to be correct than the alternative model.

In the present study, the comparison of the model will use $R^{2}$ or SSE if the models possess the same experimental points $(N)$ and parameter numbers of models $\left(N_{\mathrm{p}}\right)$. Otherwise, AIC will be employed.

\section{Results and Discussion}

3.1. Characterization of MIL-101 Samples. Figure 1 shows the XRD patterns of MIL-101 synthesized with the $\mathrm{HF} / \mathrm{H}_{2} \mathrm{BDC}$ molar ratios of $0.00,0.25$, and 0.75 . The characteristic diffractions of the samples matched well with the published XRD patterns of MIL-101 [18]. This means that the obtained materials are MIL-101. However, the peak intensity of the samples synthesized with HF is significantly higher than that of the sample synthesized without HF (MHF0). This could be due to fluorine that acts as a mineralizing agent in the hydrothermal synthesis for the formation of well crystalline microporous materials [31].

The morphology of the obtained material consists of octahedron-shaped crystals with smooth facets (Figure 2). The particle size of MIL-101 increases with the increase in the $\mathrm{HF} / \mathrm{H}_{2} \mathrm{BDC}$ ratio. The average particle size counted based on 50 particles is $234 \mathrm{~nm}$ for MHF0, $364 \mathrm{~nm}$ for MHF0.25, and $612 \mathrm{~nm}$ for MHF0.75 (Table 1).

The textural properties of the MIL-101 samples were investigated by using nitrogen adsorption/desorption isotherms. The isotherm curves belong to type IV according to IUPAC classification (Figure 3). The BET specific surface area for MHF0.25 is the highest (Table 1), and thus, MIL-101 synthesized with $\mathrm{HF} / \mathrm{H}_{2} \mathrm{BDC}=0.25$ was chosen for adsorption experiments.
TABle 1: Textural properties of MIL-101 samples.

\begin{tabular}{lcccc}
\hline Notation & $\begin{array}{c}S_{\mathrm{BET}} \\
\left(\mathrm{m}^{2} \cdot \mathrm{g}^{-1}\right)\end{array}$ & $\begin{array}{c}S_{\text {Langmuir }} \\
\left(\mathrm{m}^{2} \cdot \mathrm{g}^{-1}\right)\end{array}$ & $\begin{array}{c}V_{\text {pore }} \\
\left(\mathrm{cm}^{3} \cdot \mathrm{g}^{-1}\right)\end{array}$ & $\begin{array}{c}d_{\mathrm{TEM}} \\
(\mathrm{nm})\end{array}$ \\
\hline MHF0 & 2772 & 4652 & 1.45 & 234 \\
MHF0.25 & 3586 & 5288 & 1.85 & 364 \\
MHF0.75 & 2614 & 4381 & 1.43 & 612 \\
\hline
\end{tabular}

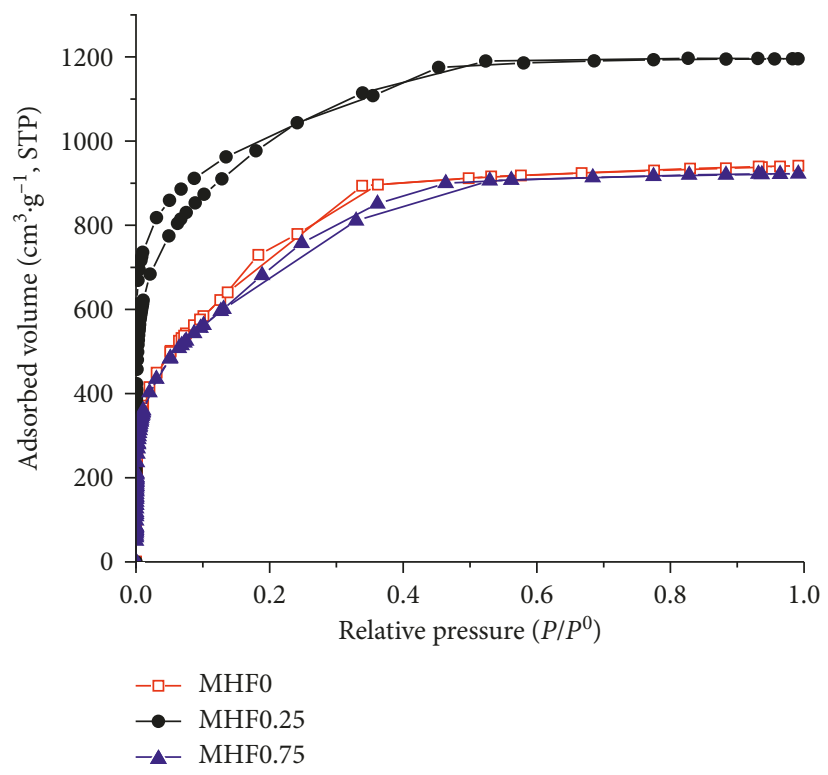

FIGURE 3: Nitrogen adsorption/desorption isotherms of MIL-101 synthesized with different molar ratios of $\mathrm{HF} / \mathrm{H}_{2} \mathrm{BDC}$.

\subsection{RDB Adsorption on MIL-101}

3.2.1. Effect of Initial Concentrations. The RDB kinetics of adsorption on MIL-101 at different initial concentrations in the range of $25-600 \mathrm{ppm}$ is illustrated in Figure 4(a). It is obvious that the adsorption capacity of RDB on MIL-101 increases when RDB initial concentration increases from 25 to $400 \mathrm{ppm}$. This might be due to the fact that, initially, the sites on the adsorbent surface are less occupied by the dye molecules, and increasing the concentration increases the interaction between the dye molecules and the adsorbent; 


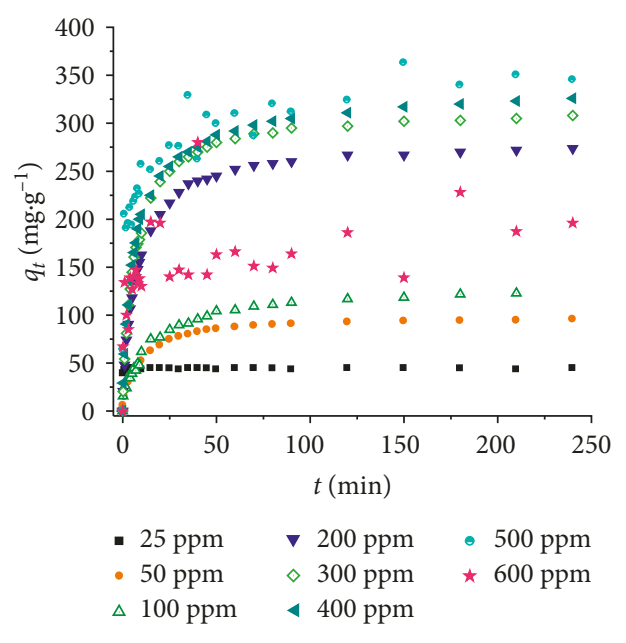

(a)

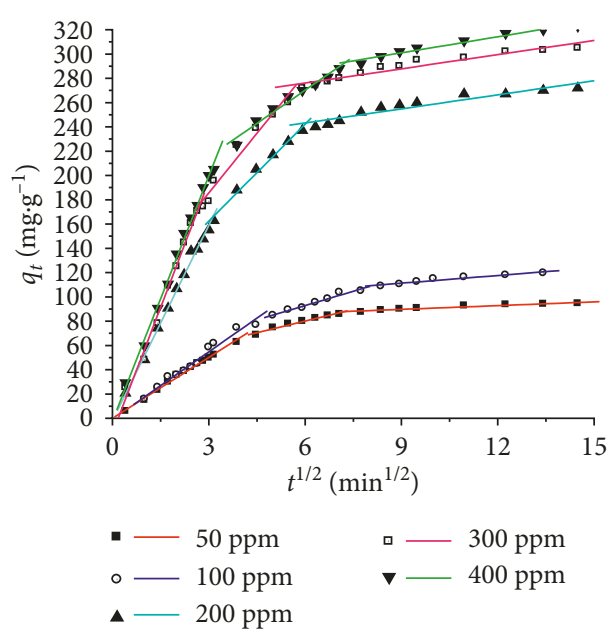

(b)

FiguRE 4: (a) RDB adsorption kinetics on MIL-101 at different concentrations; (b) stepwise lines of intraparticle diffusion plots for the adsorption of RDB on MIL-101 with different initial concentrations (adsorption condition: $V=1000 \mathrm{~mL} ; m_{\mathrm{MIL}-101}=0.5 \mathrm{~g} ; \mathrm{pH}=7.0 ;$ room temperature).

thus, more dye molecules adsorb on the surface $[10,32,33]$. In addition, the mass transfer driving force becomes larger as the initial concentration increases, and this results in higher adsorption capacity [21]. At higher concentrations $(>400 \mathrm{ppm})$, the adsorption takes place very fast during the first 15 minutes, and then, it slows down and reaches equilibrium at about 150 minutes. Meanwhile, for concentration at $25 \mathrm{ppm}$, the adsorption reaches equilibrium practically immediately, just after about 10 minutes. This might be because at low dye concentration, the driving force is very small and the adsorption takes place only on the surface of MIL-101, whereas when the dye concentration is high with large driving force, the adsorption also occurs in the pore of the adsorbent, and due to high resistance in the pores, the adsorption becomes slower and reaches equilibrium after a longer period. Furthermore, adsorption might take place in several stages. At a very high dye concentration (600 ppm), the RDB adsorption on MIL-101 does not follow the same pattern as at lower initial dye concentration (Figure 4). This might be the result of forming a colloidal solution at a high concentration of RDB [20,34].

Therefore, the RDB initial concentration from 50 to $400 \mathrm{ppm}$ is suitable for the kinetic study of adsorption on MIL-101. In this kinetic study, Weber's intraparticle diffusion model [19] was applied to study the adsorption mechanism. The values of $q_{t}$ at different times were analysed using piecewise linear regressions based on the assumption of one, two, three, and four linear segments. The $\mathrm{AIC}_{C}$ value was the criterion for determining which one is the goodness of fit (Table 2).

The data indicate that the three-linear-segment model has the lowest $\mathrm{AIC}_{C}$, and therefore, this Weber's model is the most accurate because for this criterion the lower the value, the more suitable the model. Three distinct steps can be seen on the kinetic curves: (i) instantaneous adsorption of RDB molecules within the first 7-21 minutes, (ii) a gradual attainment of the equilibrium due to the utilization of the all
TABle 2: Comparison of piecewise models of one, two, three, and four linear segments using AIC for Weber's model.

\begin{tabular}{lccccc}
\hline$C_{0}(\mathrm{ppm})$ & Number of segments & $N$ & $N_{\mathrm{p}}$ & $\mathrm{SSE}$ & $\mathrm{AIC}_{C}$ \\
\hline \multirow{4}{*}{50} & 1 & 27 & 2 & 4663116 & 330.103 \\
& 2 & 27 & 4 & 106 & 46.814 \\
& 3 & 27 & 6 & 26 & 15.678 \\
& 4 & 27 & 8 & 24 & 20.820 \\
100 & 1 & 25 & 2 & 3435 & 127.600 \\
& 2 & 25 & 4 & 287 & 70.200 \\
& 3 & 25 & 6 & 149 & 61.350 \\
& 4 & 25 & 8 & 130 & 66.245 \\
200 & 1 & 27 & 2 & 34824445 & 384.390 \\
& 2 & 27 & 4 & 1313 & 114.690 \\
& 3 & 27 & 6 & 270 & 78.333 \\
300 & 4 & 27 & 8 & 251 & 84.149 \\
& 1 & 27 & 2 & 41762504 & 389.295 \\
& 2 & 27 & 4 & 1716 & 121.922 \\
& 3 & 27 & 6 & 642 & 101.746 \\
400 & 4 & 27 & 6 & 623 & 108.745 \\
& 1 & 27 & 2 & 44322439 & 390.901 \\
& 2 & 27 & 4 & 1799 & 123.192 \\
& 3 & 27 & 6 & 245 & 75.756 \\
& 4 & 27 & 8 & 236 & 82.497 \\
\hline
\end{tabular}

active sites on the adsorbent surface, and (iii) an equilibrium attainment of RDB molecules onto MIL-101 (Figure 4(b)). At the initial concentration of $50 \mathrm{mg} \cdot \mathrm{L}^{-1}$, for example, the intercept of the first linear segment is 0.05 , and its $99 \%$ confidence interval is $(-3.14 ; 3.23)$, indicating that the intercept is not significantly different from zero. This strongly suggests that intraparticle diffusion is the rate-controlling mechanism during the first 15 minutes of adsorption. The next two linear segments do not pass through the origin because the $99 \%$ confidence intervals of their intersects do not contain zero, indicating that the intraparticle diffusion is not the only rate-limiting step and film diffusion or chemical 
TABLe 3: Parameters of Weber's three-linear-segment model (the values in parentheses are 99\% confidence intervals).

\begin{tabular}{lccccc}
\hline$C_{0}(\mathrm{ppm})$ & 50 & 100 & 200 & 300 & 400 \\
\hline Slope 1 & $16.70(15.39 ; 18.02)$ & $17.57(14.71 ; 20.43)$ & $53.65(48.86 ; 58.44)$ & $69.04(57.27 ; 80.80)$ & $67.13(62.62 ; 71.64)$ \\
Intercept 1 & $0.05(-3.14 ; 3.23)$ & $1.16(-7.37 ; 9.70)$ & $-1.97(-12.15 ; 8.21)$ & $-12.18(-34.26 ; 9.89)$ & $--2.04(-12.14 ; 8.06)$ \\
$\begin{array}{l}\text { Break point } 1 \\
\text { (minutes) }\end{array}$ & 16.46 & 21.15 & 9.77 & 7.53 & 11.08 \\
Slope 2 & $6.39(4.41 ; 8.38)$ & $7.74(3.66 ; 11.82)$ & $26.60(19.91 ; 33.28)$ & $32.72(20.63 ; 44.80)$ & $18.29(13.49 ; 23.08)$ \\
Intercept 2 & $41.67(29.92 ; 53.42)$ & $46.48(19.63 ; 73.33)$ & $82.60(50.87 ; 114.33)$ & $87.51(38.08 ; 136.94)$ & $160.50(133.18 ; 187.82)$ \\
Break point 2 & 52.32 & 65.64 & 36.55 & 32.87 & 52.79 \\
(minutes) & & $2.11(1.09 ; 3.13)$ & $3.86(2.50 ; 5.22)$ & $3.90(2.83 ; 4.98)$ & $4.40(3.20 ; 5.60)$ \\
Slope 3 & $1.03(0.58 ; 1.47)$ & $92.23(81.40 ; 103.07)$ & $220.08(206.55 ; 233.60)$ & $252.69(242.26 ; 263.12)$ & $261.40(248.27 ; 274.53)$ \\
Intercept 3 & $80.49(75.64 ; 85.33)$ & 92.235 &
\end{tabular}

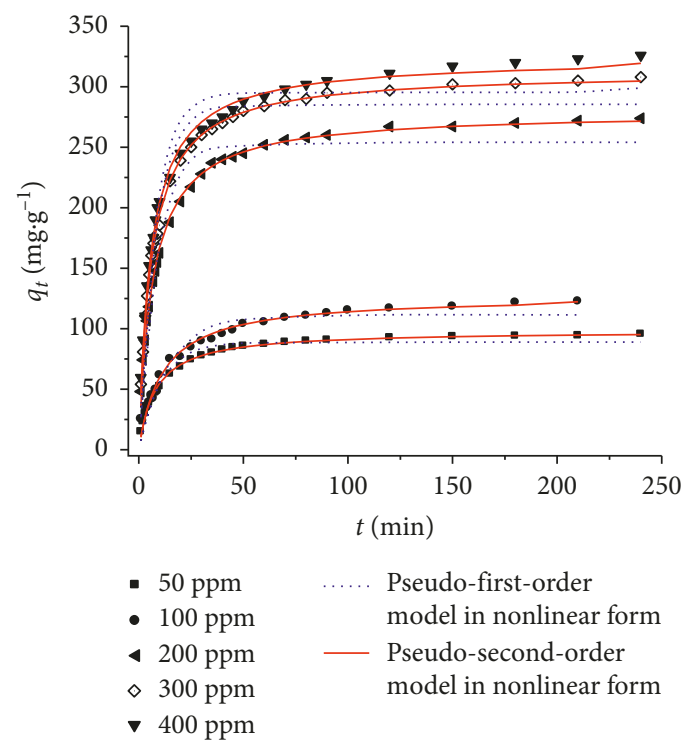

(a)

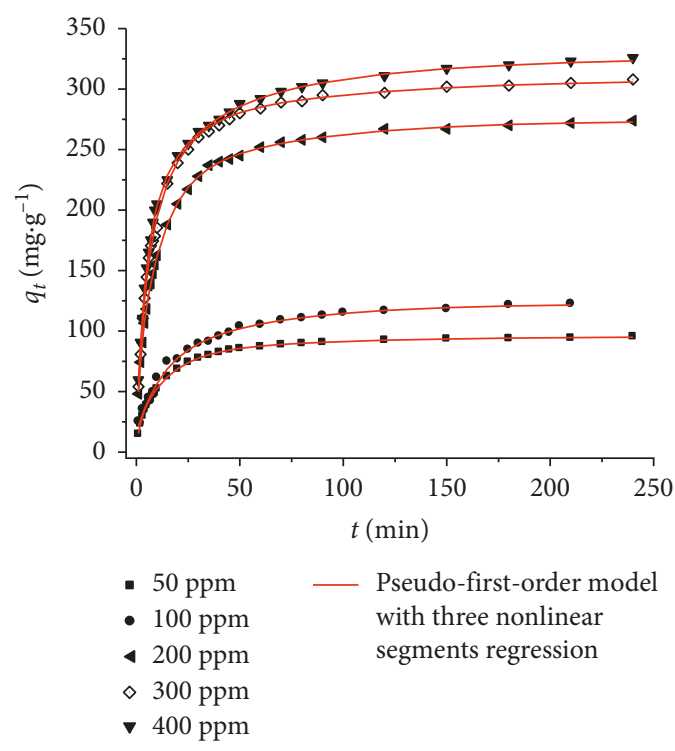

(b)

Figure 5: (a) Plots of pseudo-first- and pseudo-second-order adsorption kinetics; (b) plots of three pseudo-first-order adsorption kinetics of RDB on MIL-101.

reaction might take place during these periods of adsorption $[20,33]$. This behavior is found for all concentrations. The intraparticle parameters are illustrated in Table 3.

The data indicate that the film thickness (intercept 2 and intercept 3) increases with the increase in initial RDB concentration. This suggests that film diffusion controls the adsorption process in the last two steps. In the first step, the intraparticle diffusion parameter, $k_{\mathrm{p} 1}$, increases as initial $\mathrm{RDB}$ concentration increases. These results suggest that intraparticle diffusion controls the rate in the initial step of the adsorption process.

In addition, the nature of the rate-limiting step is also confirmed by plotting the intraparticle diffusion constant, $k_{\mathrm{p} 1}$, versus the first power of the initial concentration. If $k_{\mathrm{p} 1}$ is proportional to the initial dye concentration, the adsorption process is controlled by film diffusion, whereas, if intraparticle diffusion limits the adsorption process, the relationship between dye concentrations and $k_{\mathrm{p} 1}$ will not be linear $[20,35]$. For the adsorption of RDB onto MIL-101, the plot of $k_{\mathrm{p} 1}$ versus the initial concentration $\left(C_{0}\right)$ is not linear $\left(R^{2}=0.875\right.$; $p=0.02>0.01)$, confirming that the intraparticle diffusion mechanism controlled the adsorption in the initial step.

To study the formal kinetics of the RDB adsorption on MIL-101, the experimental data were subjected to pseudofirst-order and pseudo-second-order kinetics in the nonlinear form. The results are shown in Figure 5(a) and Table 4.

The experimental points in Figure 5(a) are very far from the first-order model curves, whereas they practically coincide with the second-order kinetic curves. From Table 4, we can see that the pseudo-second-order kinetic model has lower AIC values than the pseudo-first-order kinetic model. This means that the pseudo-second-order kinetic model explains the experimental data more appropriately. These results are consistent with those of other reports [30, 36, 37]. The rate constant $k_{2}$ calculated from the pseudo-secondorder kinetic model decreases as the initial RDB concentration increases. This indicates that chemisorption is significant in the rate-limiting step, involving valence forces through sharing or exchange of electrons between RDB and MIL-101. 
TABLE 4: Kinetic parameters for pseudo-first-order and pseudo-second-order kinetic models of RDB adsorption on MIL-101.

\begin{tabular}{|c|c|c|c|c|c|c|c|}
\hline \multirow{2}{*}{$C_{0}(\mathrm{ppm})$} & \multirow{2}{*}{$q_{\mathrm{e}(\exp )}\left(\mathrm{mg} \cdot \mathrm{g}^{-1}\right)$} & \multicolumn{3}{|c|}{ Pseudo-first-order kinetics } & \multicolumn{3}{|c|}{ Pseudo-second-order kinetics } \\
\hline & & $q_{\mathrm{e}, \mathrm{cal}}\left(\mathrm{mg} \cdot \mathrm{g}^{-1}\right)$ & $k_{1} \cdot 10^{2}\left(\min ^{-1}\right)$ & $\mathrm{AIC}_{C}$ & $q_{\mathrm{e}, \mathrm{cal}}\left(\mathrm{mg} \cdot \mathrm{g}^{-1}\right)$ & $k_{2} \cdot 10^{4}\left(\mathrm{~g} \cdot \mathrm{mg}^{-1} \cdot \mathrm{min}^{-1}\right)$ & $\mathrm{AIC}_{C}$ \\
\hline 50 & 95.51 & 88.89 & 9.52 & 88.654 & 98.42 & 12.76 & 35.537 \\
\hline 100 & 122.78 & 111.65 & 6.92 & 112.215 & 126.91 & 6.78 & 90.873 \\
\hline 200 & 273.80 & 253.99 & 11.12 & 149.668 & 279.09 & 5.36 & 108.087 \\
\hline 300 & 308.00 & 286.07 & 11.99 & 146.452 & 313.32 & 5.33 & 86.556 \\
\hline 400 & 325.99 & 295.34 & 12.81 & 156.611 & 323.38 & 5.33 & 108.258 \\
\hline
\end{tabular}

TABLE 5: Kinetic parameters of three-nonlinear-segment regression for pseudo-first-order kinetic model of RDB adsorption on MIL-101.

\begin{tabular}{lcccccccccc}
\hline$C_{0}(\mathrm{ppm})$ & $q_{1}\left(\mathrm{mg} \cdot \mathrm{g}^{-1}\right)$ & $k_{1}\left(\mathrm{~min}^{-1}\right)$ & $R^{2}$ & $q_{2}\left(\mathrm{mg} \cdot \mathrm{g}^{-1}\right)$ & $k_{2}\left(\mathrm{~min}^{-1}\right)$ & $R^{2}$ & $q_{3}\left({\left.\mathrm{mg} \cdot \mathrm{g}^{-1}\right)} k_{3}\left(\mathrm{~min}^{-1}\right)\right.$ & $R^{2}$ & $q_{\mathrm{e}, \mathrm{exp}}\left(\mathrm{mg} \cdot \mathrm{g}^{-1}\right)$ \\
\hline 50 & 16.50 & 0.01 & 0.99 & 57.48 & 0.07 & 0.97 & 18.39 & 0.57 & 0.93 & 95.51 \\
100 & 24.42 & 0.02 & 0.97 & 18.69 & 0.02 & 0.97 & 65.99 & 0.13 & 0.93 & 122.78 \\
200 & 56.96 & 0.02 & 0.99 & 49.92 & 0.61 & 0.99 & 153.93 & 0.09 & 0.91 & 273.80 \\
300 & 105.82 & 0.29 & 0.99 & 142.62 & 0.07 & 0.96 & 44.04 & 0.01 & 0.93 & 308.00 \\
400 & 156.17 & 0.23 & 0.99 & 63.80 & 0.01 & 0.97 & 83.86 & 0.05 & 0.97 & 325.99 \\
\hline
\end{tabular}

TABLE 6: $\mathrm{AIC}_{C}$ values of the different kinetic models.

\begin{tabular}{lcccc}
\hline Model & & \multicolumn{2}{c}{$\mathrm{AIC}_{C}$} \\
& $50 \mathrm{ppm}$ & $100 \mathrm{ppm}$ & $200 \mathrm{ppm}$ & $300 \mathrm{ppm}$ \\
\hline Pseudo-first-order kinetics & 88.65 & 112.22 & 149.67 & 146.45 \\
Pseudo-second-order kinetics & 35.54 & 90.87 & 108.09 & 86.56 \\
Pseudo-first-order kinetics with three segments & -48.99 & 56.84 & 87.84 & 66.30 \\
\hline
\end{tabular}

However, as mentioned earlier, in the present study, the adsorption process took place in three steps. Although the pseudo-second-order kinetic model accounts for the chemisorption nature well, it does not support the multisegment adsorption process. Al-Ghouti et al. [20] mentioned this problem and tried to analyse the adsorption as a threestep process with three linear segments on the kinetic plots by using the graphical approach method. Therefore, in this study, we analyse the adsorption process in the same way; that is, the kinetic plot is also divided into three segments each of which follows the pseudo-first-order adsorption kinetics.

The three-step kinetic rate equation was expressed as follows: $q_{t}=q_{0}+q_{1} \cdot\left(1-e^{-k_{1} \cdot t}\right)+q_{2} \cdot\left(1-e^{-k_{2} \cdot t}\right)+q_{3} \cdot\left(1-e^{-k_{3} \cdot t}\right)$,

where $q_{1}, q_{2}$, and $q_{3}$ are the amount of dye adsorbed at time $t$ after the subsequent kinetic steps ( $\left.\mathrm{mg}^{-1} \mathrm{~g}^{-1}\right) ; q_{0}$ is the amount of dye adsorbed at time $t=0$; and $k_{1}, k_{2}$, and $k_{3}$ are the kinetic rate constants associated with each kinetic step. At $t=\infty$, when the adsorption reaches equilibrium, $q_{t}=q_{\mathrm{e}}$, and $q_{\mathrm{e}}=q_{0}+q_{1}+q_{2}+q_{3}$. Therefore, (22) can be written as

$$
q_{t}=q_{\mathrm{e}}-q_{1} \cdot e^{-k_{1} \cdot t}-q_{2} \cdot e^{-k_{2} \cdot t}-q_{3} \cdot e^{-k_{3} \cdot t}
$$

The values of $q_{1}, q_{2}$, and $q_{3}$ and $k_{1}, k_{2}$, and $k_{3}$ can be obtained using nonlinear regression by means of the Statistical Package for Scientific Social 20 (SPSS 20).
The three-nonlinear-segment regressions using the pseudo-first-order kinetic model for the RDB adsorption on MIL-101 are shown in Figure 5(b) and Table 5. High determination coefficients $(0.91-0.99)$ indicate the appropriateness of the model. In addition, the $\mathrm{AIC}_{C}$ values for the pseudo-first-order kinetics with three segments are also the lowest of the three kinetic models (Table 6). This further confirms the best fit of the pseudo-first-order kinetics with three segments with the experimental data. The finding is also consistent with the analysis of the three-step adsorption process using Weber's intraparticle diffusion model.

3.2.2. Effect of Particle Size and Agitation. To study diffusion kinetics of the RDB adsorption on MIL-101 in terms of particle size, the three-linear-segment regression for the intraparticle diffusion model was applied to analyse the experimental data (Figure 6(a)). The results were the same as those of the effect of initial concentration. Intraparticle diffusion limited the adsorption rate at the initial step, and film diffusion controlled the process in the next two steps. The values of $k_{\mathrm{p} 1}$ are $14.04,29.94$, and $13.55 \mathrm{mg} \cdot \mathrm{g}^{-1} \cdot \mathrm{min}^{-0.5}$ for MHF0, MHF0.25, and MHF0.75, respectively. Theoretically, the intraparticle diffusion constant, $k_{\mathrm{p} 1}$, versus the inverse particle diameter, $d^{-1}$, did not give a straight line, and the conclusion for this is that the intraparticle diffusion was not the only operative mechanism [20]. In fact, in our study, this line was not linear $\left(R^{2}=0.008, p=0.943\right)$ although MIL-101 is a porous material; hence, we cannot rely on the particle size (external surface area) to confirm the adsorption mechanism. Therefore, the intraparticle diffusion 


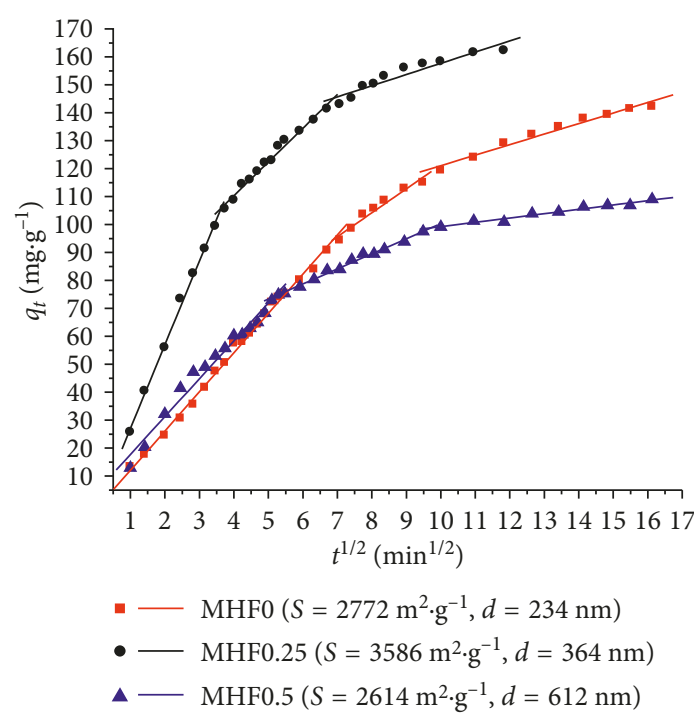

(a)

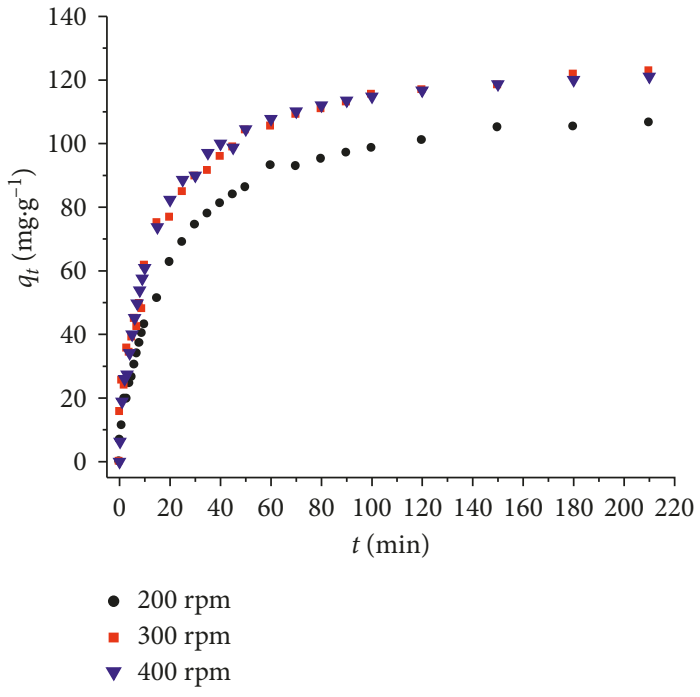

(b)

Figure 6: (a) Plots of the three-linear-segment regression of intraparticle diffusion model; (b) effect of stirring speed on the adsorption capacity of RDB on MIL-101.

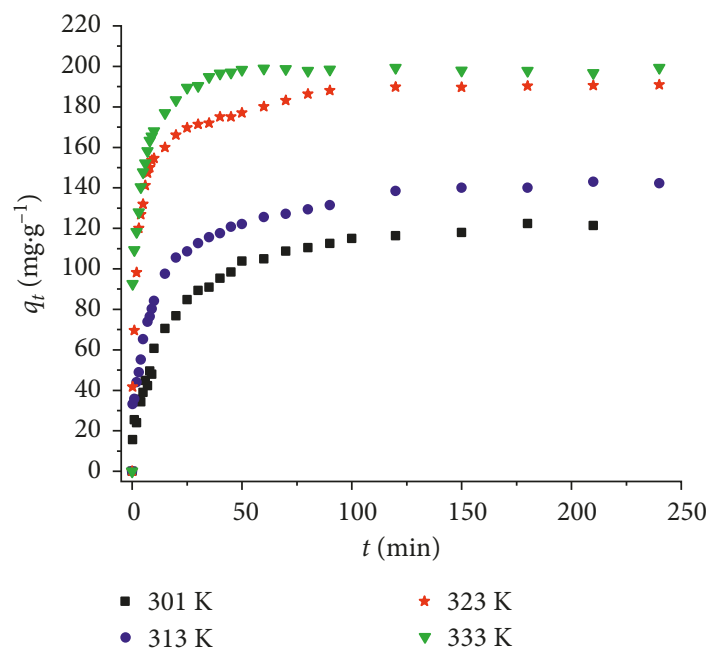

(a)

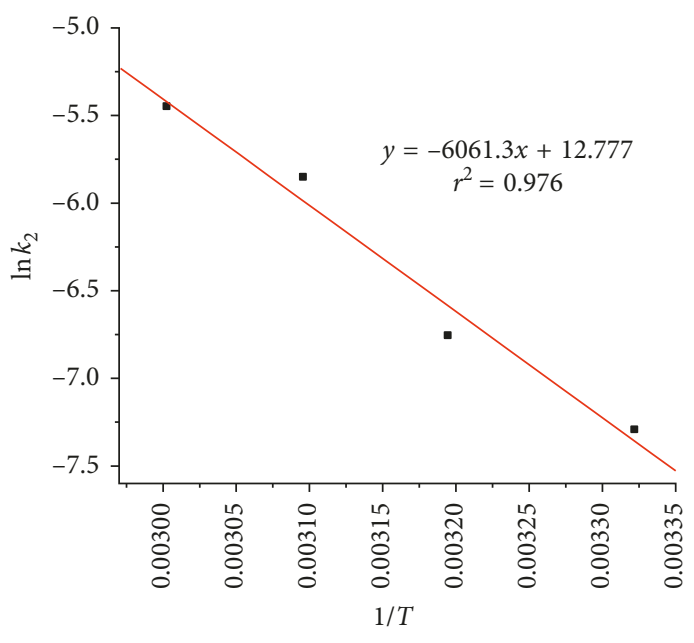

(b)

Figure 7: (a) RDB adsorption kinetics on MIL-101 at different temperatures; (b) Arrhenius plot.

mechanism controlled the initial step of the adsorption process. As can be seen from Figure 6(a), the adsorption capacity depends on the specific area rather than the particle size. This is because, for porous materials, the external surface contributes very little to the total surface area. In terms of particle size, only external surface area is concerned.

Stirring speed affects not only the distribution of the dye molecules in the bulk solution but also the formation of the external boundary film. Increasing stirring speed decreases the film thickness and thus the resistance to mass transfer around the adsorbent particle and increases the mobility of the whole system [38]. The effect of the stirring speed on RDB adsorption on MIL-101 was carried out with three values: 200, 300, and $400 \mathrm{rpm}$ (Figure 6(b)). It is evident that the adsorption capacity increased when the stirring speed increases from $200 \mathrm{rpm}$ to $300 \mathrm{rpm}$ and remained practically stable at $400 \mathrm{rpm}$. As the stirring speed increases the diffusion rate, the resistance of the solution becomes small. After a certain stirring rate, the external resistance no longer affects the sorption process.

3.2.3. Thermodynamic Studies. Temperature significantly affected the RDB adsorption over MIL-101. When the temperature increased from $301 \mathrm{~K}$ to $333 \mathrm{~K}$, the adsorption capacity increased rapidly from $120 \mathrm{mg} \cdot \mathrm{g}^{-1}$ to $190 \mathrm{mg} \cdot \mathrm{g}^{-1}$ (Figure $7(\mathrm{a})$ ). This indicates that the RDB adsorption on MIL-101 is an endothermic process. Similar results were 
TABLE 7: Thermodynamic parameters of RDB adsorption on MIL101.

\begin{tabular}{lccc}
\hline Temperature $(\mathrm{K})$ & $\begin{array}{c}\Delta H^{0} \\
\left(\mathrm{~kJ} \cdot \mathrm{mol}^{-1}\right)\end{array}$ & $\begin{array}{c}\Delta S^{0} \\
\left(\mathrm{~J} \cdot \mathrm{mol}^{-1} \cdot \mathrm{T}^{-1}\right)\end{array}$ & $\begin{array}{c}\Delta G^{0} \\
\left(\mathrm{~kJ} \cdot \mathrm{mol}^{-1}\right)\end{array}$ \\
\hline 301 & & & -1.014 \\
313 & 13.66 & 457.27 & -6.501 \\
323 & & & -11.074 \\
333 & & & -15.646 \\
\hline
\end{tabular}

observed in the adsorption of uranine [9] and methyl orange [32] on MIL-101.

It is obvious that high temperature increased the diffusion rate of the dye molecules across the external boundary layer and in the internal pores of the adsorbent particle. This was the result of the decrease in the viscosity of the solution. In addition, the increase in adsorption capacity could also be ascribed to the increase in the number of active sites on the MIL-101 surface due to the decrease in the hydrogen bonding between adsorbed water and the adsorbent making more sites available for RDB molecules.

The pseudo-second-order kinetic model was more consistent with the kinetic data than the pseudo-first-order kinetic model in the temperature range of $301 \mathrm{~K}$ to $333 \mathrm{~K}$. Hence, the rate constant $k_{2}$ was used to calculate the thermodynamic parameters. The $E_{\mathrm{a}}$ value obtained from the slope of the linear plot of $\ln k_{2}$ versus $T^{-1}(F(3)=59.15$; $R^{2}=0.98, p<0.01$ ) (Figure $7(\mathrm{~b})$ ) was $50.39 \mathrm{~kJ} \cdot \mathrm{mol}^{-1}$. This large activation energy (over $42 \mathrm{~kJ} \cdot \mathrm{mol}^{-1}$ ) implies that chemisorption controlled the adsorption of RDB on MIL101.

The thermodynamic parameters of the system, namely, $\Delta H^{0}, \Delta S^{0}$, and $\Delta G^{0}$ were evaluated using the van't Hoff equation to determine the spontaneity of the adsorption process. The positive value of $\Delta H^{0}$ (Table 7) suggested an endothermic adsorption process. The positive value of $\Delta S^{0}$ indicated the increase in the randomness at the solid-liquid interface during the adsorption of RDB molecules on the adsorbent [39]. The large negative values of $\Delta G^{0}$ strongly recommended the spontaneous RDB adsorption on MIL101. The more negative value at higher temperatures suggested that the spontaneity increased with temperature. As the change of Gibbs free energy was negative and accompanied by the positive standard entropy change, the adsorption reaction was spontaneous with high affinity.

3.2.4. Effect of $p H$. The $\mathrm{pH}$ of the solution affects the dye adsorption process because it can alternate both dye ionization and the ionic state of the surface of the adsorbent. Figure 8(a) presents the effect of $\mathrm{pH}$ on $\mathrm{RDB}$ adsorption from aqueous solutions. The RDB adsorption capacity of MIL-101 increased slightly with $\mathrm{pH}$ from 3 to 5 , followed by a significant increase with $\mathrm{pH}$ from 5 to 9 . The $\mathrm{pH}_{\mathrm{pzc}}$ (the point of zero charge) of MIL-101 determined by the $\mathrm{pH}$ drift method [40] is around 5 (Figure $8(\mathrm{~b})$ ). This $\mathrm{pH}_{\mathrm{pzc}}$ implies that the surface of the MIL-101 is positively charged when $\mathrm{pH}$ of the solution is below 5 , whereas the surface of adsorbent becomes negatively charged at $\mathrm{pH}$ above 5 .
Increasing $\mathrm{pH}$ led to an increase in adsorption capacity, suggesting that the adsorption could follow a mechanism other than electrostatic interaction. The $\pi-\pi$ stacking interaction between the aromatic rings of the RDB and the aromatic rings of terephthalate in the MIL-101 framework was also thought to contribute to the RDB adsorption capacity. In addition, the coordination of the oxygen of the carboxyl group in the RDB molecules with the unsaturated $\mathrm{Cr}$ (III) ions in the MIL-101 framework is also responsible for more efficient adsorption. A possible mechanism of RDB adsorption on MIL-101 is illustrated in Scheme 2.

3.2.5. Adsorption Isotherms of RDB on MIL-101. To describe the adsorption isotherms, Langmuir, Freundlich, RedlichPeterson, Sips, and Toth equations were selected for use in this study. The determination of parameters of isotherm models is often based on the linear regression. However, linear regression requires the transformation of the original equation into a linear form that induces a problem related to abuse $R^{2}$. For example, the popular linear form of the Langmuir model is $C_{\mathrm{e}} / q_{\mathrm{e}}=C_{\mathrm{e}} / q_{\mathrm{m}}+1 /\left(K_{\mathrm{L}} \cdot q_{\mathrm{m}}\right)$, in which $C_{\mathrm{e}}$ is present in both independent and dependent variables [41]. Some papers $[42,43]$ reported that the linear form is less accurate than the nonlinear form in some cases of isotherm sorption as well as sorption kinetics. For these reasons, the isotherm equations in the nonlinear form are used in this study. Figure 9 shows the graphs that plot $q_{\mathrm{e}}$ versus $C_{\mathrm{e}}$ using the Langmuir, Freundlich, RedlichPeterson, Sips, and Toth models. These models displayed lines around the experimental data, indicating that they all could describe the experimental data well.

The parameters of the isotherm models calculated using nonlinear regression are listed in Table 8. Except $q_{\mathrm{m}}$ derived from the Sips model $\left(290.15 \mathrm{mg} \cdot \mathrm{g}^{-1}\right)$, the values of $q_{\mathrm{m}}$ from the Redlich-Peterson and Toth models are fairly similar to that of $q_{\mathrm{m}}$ obtained from the Langmuir model due to the parameter of $n$ being close to 1 .

Based on the values of SSE as well as the coefficient of determination, we can see that the Langmuir, RedlichPeterson, and Toth models provide a higher goodness of fit than the Sips and Freundlich models (Table 8).

To compare models with the same parameters and experimental points, SSE or $R^{2}$ are frequently utilized to estimate the goodness of fit. As a result, it is obvious that the experimental data fit the Langmuir model better than the Freundlich model. However, for models with a different degree of freedom, Akaike's information criterion [44] is used instead.

Table 9 shows the comparison of the Langmuir model with other models in the study. The value of ER $(15.1,15.8$, 28.6, 1875.1) indicates that the Langmuir model is more appropriate than the Toth, Redlich-Peterson, and Freundlich models, implying that the monomolecular-layer nature is prevalent for the adsorption of RDB onto MIL- 101 .

It is obvious that the piecewise linear regression is a useful approach to analyse the multilinearity. In order to find out the parameters in regression equations, the initial variables should be provided. If the initial variable is as far 


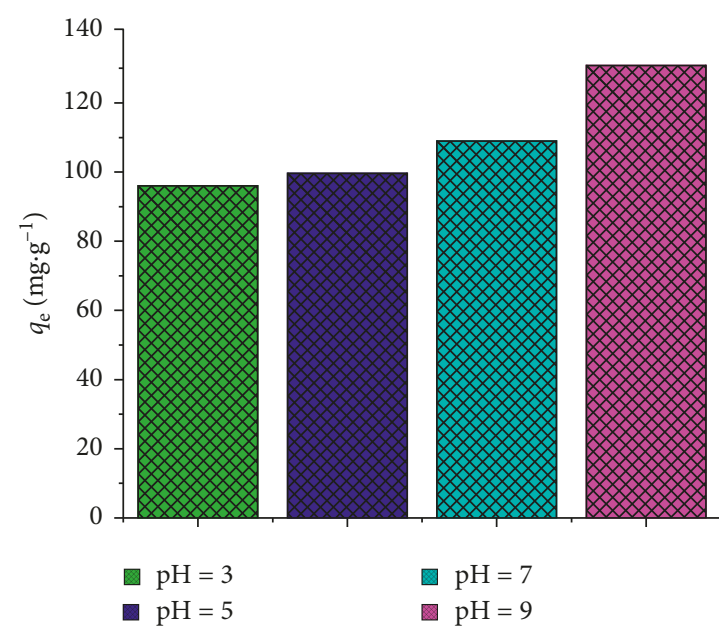

(a)

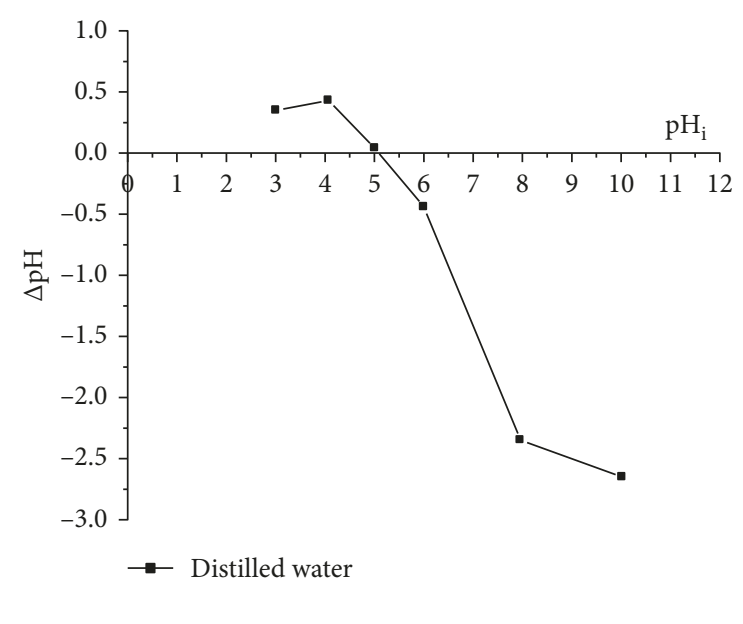

(b)

FIgURE 8: (a) Effect of $\mathrm{pH}$ on adsorption capacity; (b) the point of zero charge determined using the $\mathrm{pH}$ drift method.

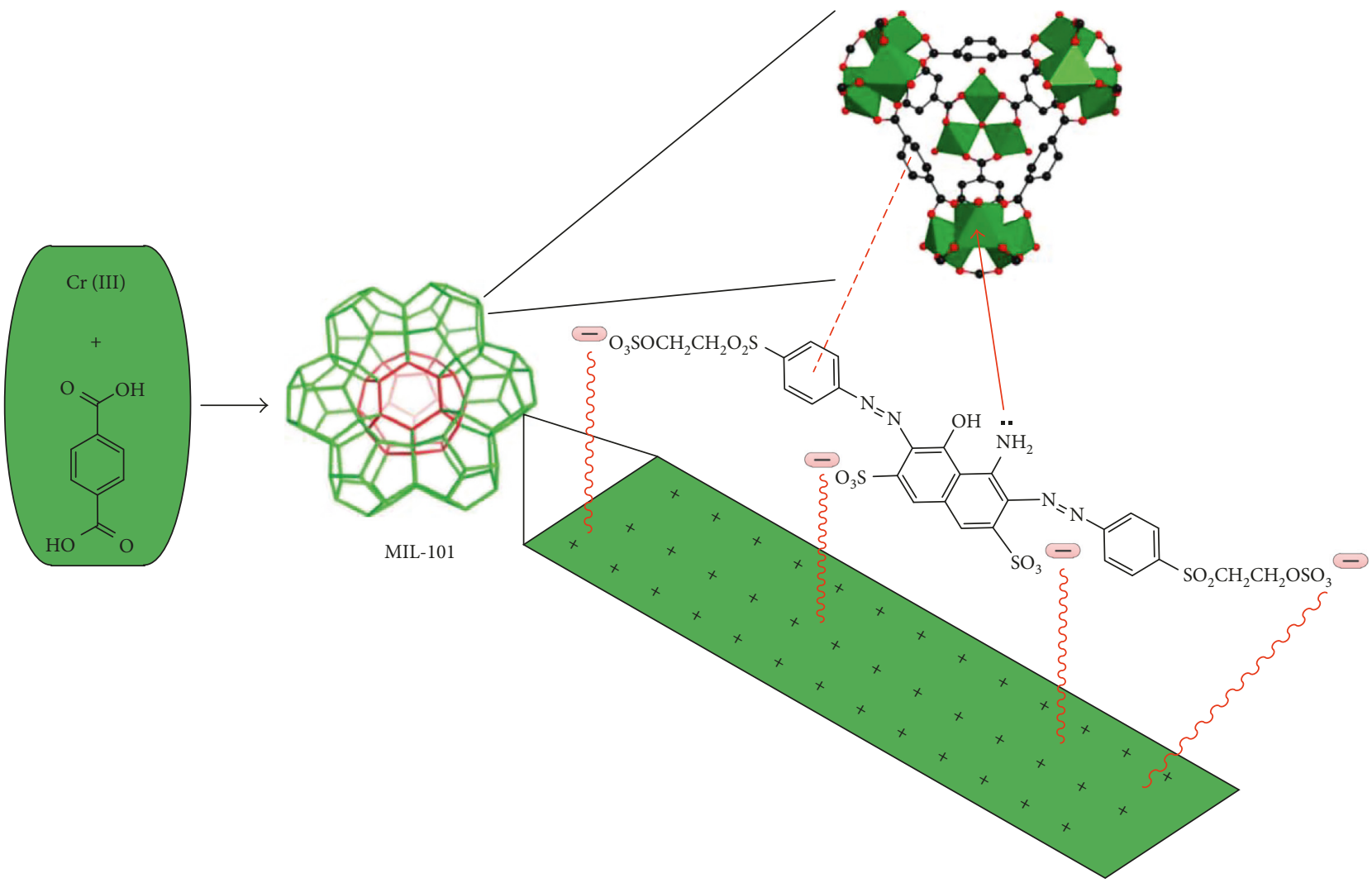

Scheme 2: Proposed mechanisms of RDB adsorption on MIL-101.

away as the real parameters, the solving equation is easy to go wrong due to finding the local minimum. This problem needs to study further. In this study, using AIC is proved to be effective for evaluating the goodness of fit for models which have a different number of parameters and experimental points. However, the application of AIC in adsorption filed is limited. Clarification of the meaning behind the AIC should be clarified.
3.2.6. Reusability of $M I L-101$. In order evaluate the reusability of MIL-101 in the removal of RDB, used MIL-101 samples were regenerated by washing with a $0.25 \mathrm{M} \mathrm{NaOH}$ solution for $5 \mathrm{~h}$ under sonication and drying for 10 hours at $100^{\circ} \mathrm{C}$. Three generations were performed, and the RDB adsorption capacity decreases slightly (96.5\%) and remained at around $120 \mathrm{mg} \cdot \mathrm{g}^{-1}$ (Figure 10(a)). Furthermore, MIL-101 seems to be stable under adsorption conditions since the 


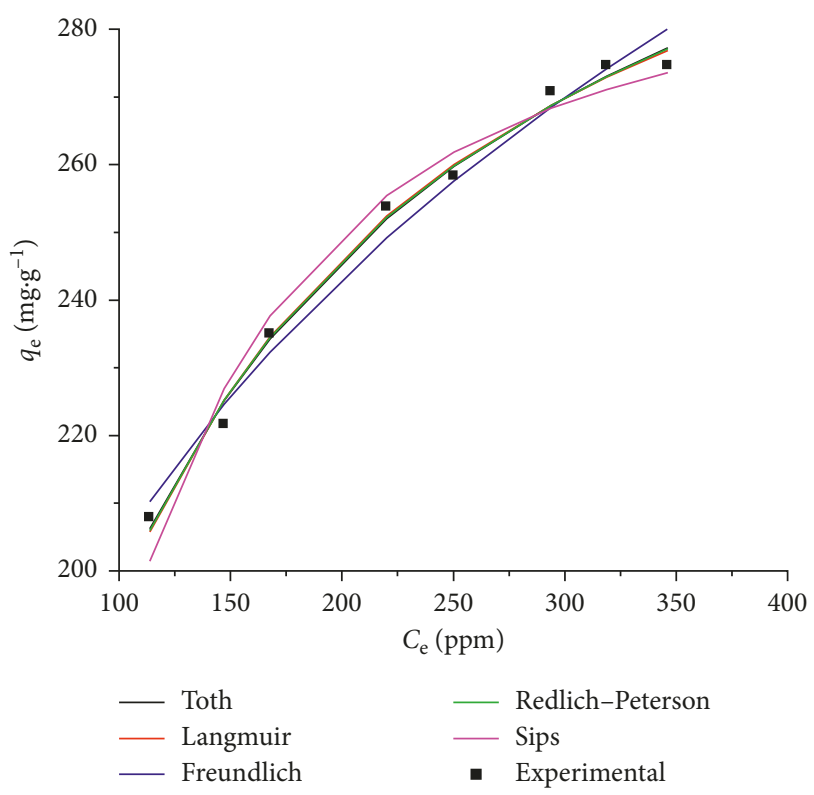

FIGURE 9: Plot of adsorption isotherms of RDB on MIL-101 using different models.

TABLE 8: Parameters of isotherm models.

\begin{tabular}{|c|c|c|c|c|c|c|}
\hline Model & $\begin{array}{c}q_{\mathrm{m}} \\
\left(\mathrm{mg} \cdot \mathrm{g}^{-1}\right)\end{array}$ & $\begin{array}{c}K_{\mathrm{L}}, K_{\mathrm{F}}, K_{\mathrm{T}}, \\
K_{\mathrm{R}}, \text { or } K_{\mathrm{S}}\end{array}$ & $\begin{array}{c}a_{\mathrm{R}} \\
\text { or } a_{\mathrm{S}}\end{array}$ & $\begin{array}{l}n, b_{\mathrm{R}}, \\
\text { or } b_{\mathrm{S}}\end{array}$ & SSE & $R^{2}$ \\
\hline Langmuir & 333.30 & 0.014 & - & - & 34.14 & 0.992 \\
\hline Freundlich & 307.85 & 62.090 & - & 3.88 & 77.55 & 0.983 \\
\hline Toth & 346.28 & 38.266 & - & 0.88 & 33.43 & 0.993 \\
\hline $\begin{array}{l}\text { Redlich- } \\
\text { Peterson }\end{array}$ & 300.26 & 4.957 & 65 & 0.98 & 33.81 & 0.993 \\
\hline Sips & 290.15 & 0.144 & 0.0005 & 1.78 & 110.19 & 0.976 \\
\hline
\end{tabular}

TABle 9: Comparison of the Langmuir model with others using evidence ratio (ER).

\begin{tabular}{lccc}
\hline Model comparison & $\mathrm{AIC}_{C}$ & $N_{\mathrm{p}}$ & $\mathrm{ER}$ \\
\hline \multirow{2}{*}{ Langmuir/Toth } & 18.0 & 2 & \multirow{2}{*}{15.1} \\
\multirow{2}{*}{ Langmuir/Redlich-Peterson } & 23.4 & 3 & \\
& 18.0 & 2 & 15.8 \\
Langmuir/Sips & 23.5 & 3 & \\
\multirow{2}{*}{ Langmuir/Freundlich } & 18.0 & 2 & \multirow{2}{*}{1785.1} \\
& 33.0 & 3 & \\
& 18.0 & 2 & 26.6 \\
\hline
\end{tabular}

XRD patterns of generated MIL-101 samples remained practically unchanged (Figure 10(b)).

\section{Conclusions}

MIL-101 was synthesized using the hydrothermal process. The particle size of MIL-101 could be controlled by adjusting the molar ratio of $\mathrm{HF} / \mathrm{H}_{2}$ BDA. MIL-101 can serve as a useful adsorbent for RDB under batch conditions. The synthesized MIL-101 material displays high adsorption capacity and can be reused. Piecewise linear regression allows to objectively

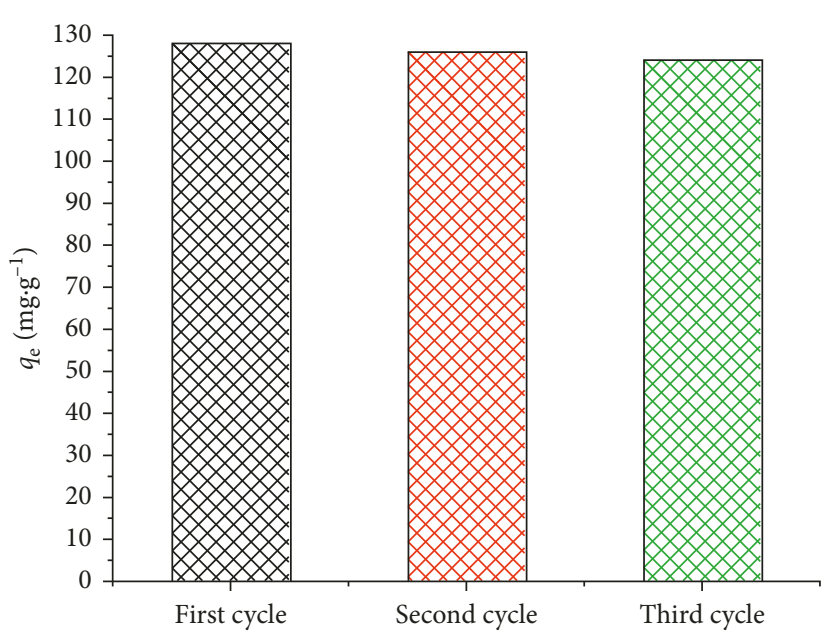

(a)

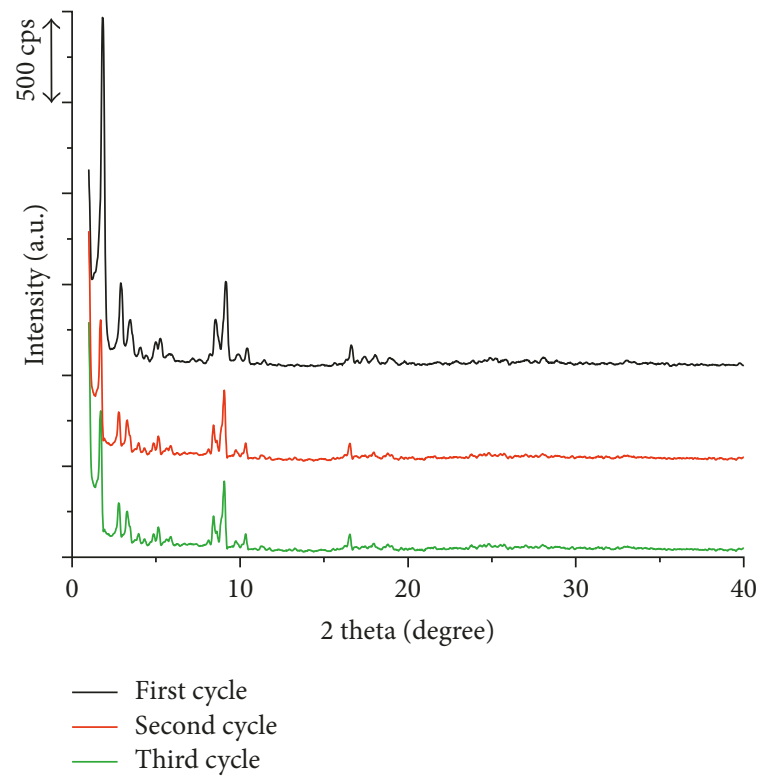

(b)

FIGURE 10: (a) Effect of regeneration cycles of ZIF-67 adsorbents on the adsorption of RDB; (b) the XRD patterns of ZIF-67 after three cycles $\left(V=100 \mathrm{~mL} ; C_{\mathrm{RDB}}=100 \mathrm{mg} \cdot \mathrm{L}^{-1}, m_{\mathrm{MIL}-101} / V_{\mathrm{RDB}}=0.1 \mathrm{~g} / 100 \mathrm{~mL}\right.$; shaking time $=12$ hours).

analyse the experimental data using Weber's intraparticle diffusion and pseudo-kinetic adsorption models during the sorption process. The results of kinetic analysis suggested that the mechanism of the sorption of RDB on MIL-101 might take place throughout the three steps: (i) film diffusion that dominates at the beginning of the process, (ii) chemisorption that monitors the subsequent period of the process, and (iii) intraparticle diffusion, where the adsorption significantly slowed down. The best fit of the pseudo-firstorder kinetics with three segments with the experimental data is consistent with the analysis of the three-step adsorption process using Weber's intraparticle diffusion model. Akaike's information criterion was employed to compare different isotherm models with a different degree of freedom. The equilibrium data of RDB onto MIL-101 fitted well to the Langmuir model rather than the Freundlich, Sips, 
Toth, and Redlich-Peterson models. As the change of Gibbs free energy was negative and accompanied by the positive standard entropy change, the adsorption process was spontaneous with high affinity.

\section{Data Availability}

The data used to support the findings of this study are available from the corresponding author upon request.

\section{Conflicts of Interest}

The authors declare that they have no conflicts of interest.

\section{References}

[1] D. Z. Van, P. Frank, and S. Villaverde, "Combined anaerobic-aerobic treatment of azo dyes-a short review of bioreactor studies," Water Research, vol. 39, no. 8, pp. 1425-1440, 2005.

[2] W. H. Cheung, Y. S. Szeto, and G. McKay, "Intraparticle diffusion processes during acid dye adsorption onto chitosan," Bioresource Technology, vol. 98, no. 15, pp. 2897-2904, 2007.

[3] J. Labanda, J. Sabaté, and J. Llorens, "Experimental and modeling study of the adsorption of single and binary dye solutions with an ion-exchange membrane adsorber," Chemical Engineering Journal, vol. 166, no. 2, pp. 536-543, 2011.

[4] S. Chen, J. Zhang, C. Zhang, Q. Yue, Y. Li, and C. Li, "Equilibrium and kinetic studies of methyl orange and methyl violet adsorption on activated carbon derived from Phragmites australis," Desalination, vol. 252, no. 1-3, pp. 149-156, 2010.

[5] Y. Li and R. T. Yang, "Hydrogen storage in metal-organic and covalent-organic frameworks by spillover," AIChE Journal, vol. 54, no. 1, pp. 269-279, 2008.

[6] P. L. Llewellyn, S. Bourrelly, C. Serre et al., "High uptakes of $\mathrm{CO}_{2}$ and $\mathrm{CH}_{4}$ in mesoporous metal-organic frameworks MIL100 and MIL-101," Langmuir, vol. 24, no. 14, pp. 7245-7250, 2008.

[7] T. K. Trung, N. A. Ramsahye, P. Trens et al., "Adsorption of $\mathrm{C}_{5}-\mathrm{C}_{9}$ hydrocarbons in microporous MOFs MIL-100(Cr) and MIL-101(Cr): a manometric study," Microporous and Mesoporous Materials, vol. 134, no. 1-3, pp. 134-140, 2010.

[8] E. Haque, J. E. Lee, I. T. Jang et al., "Adsorptive removal of methyl orange from aqueous solution with metal-organic frameworks, porous chromium-benzenedicarboxylates," Journal of Hazardous Materials, vol. 181, no. 1-3, pp. 535-542, 2010.

[9] F. Leng, W. Wang, X. J. Zhao, X. L. Hu, and Y. F. Li, “Adsorption interaction between a metal-organic framework of chromium-benzenedicarboxylates and uranine in aqueous solution," Colloids and Surfaces A: Physicochemical and Engineering Aspects, vol. 441, pp. 164-169, 2014.

[10] C. Chen, M. Zhang, Q. Guan, and W. Li, "Kinetic and thermodynamic studies on the adsorption of xylenol orange onto MIL-101(Cr)," Chemical Engineering Journal, vol. 183, pp. 60-67, 2012.

[11] P. A. Soloman, C. A. Basha, M. Velan, V. Ramamurthi, K. Koteeswaran, and N. Balasubramanian, "Electrochemical degradation of Remazol black B dye effluent," Clean-Soil, Air, Water, vol. 37, no. 11, pp. 889-900, 2009.
[12] N. F. Cardoso, R. B. Pinto, E. C. Lima et al., "Removal of remazol black $B$ textile dye from aqueous solution by adsorption," Desalination, vol. 269, no. 1-3, pp. 92-103, 2011.

[13] V. P. Ranjusha, R. Pundir, K. Kumar, M. G. Dastidar, and T. R. Sreekrishnan, "Biosorption of Remazol black B dye (Azo dye) by the growing Aspergillus flavus," Journal of Environmental Science and Health. Part A, vol. 45, no. 10, pp. 1256-1263, 2010.

[14] M. T. Thanh, T. V. Thien, V. T. T. Chau, P. D. Du, N. P. Hung, and D. Q. Khieu, "Synthesis of iron doped zeolite imidazolate framework- 8 and its remazol deep black RGB dye adsorption ability," Journal of Chemistry, vol. 2017, Article ID 504597, 18 pages, 2017

[15] M. T. Thanh, T. V. Thien, P. D. Du, and D. Q. Khieu, "Iron doped zeolitic imidazolate framework (Fe-ZIF-8): synthesis and photocatalytic degradation of RDB dye in Fe-ZIF-8," Journal of Porous Materials, vol. 25, no. 3, pp. 857-869, 2017.

[16] M. Roosta, M. Ghaedi, and A. Asfaram, "Simultaneous ultrasonic-assisted removal of malachite green and safranin $\mathrm{O}$ by copper nanowires loaded on activated carbon: central composite design optimization," RSC Advances, vol. 5, no. 70, pp. 57021-57029, 2015.

[17] H. Motulsky and A. Christopoulos, Fitting Models to Biological Data Using Linear and Nonlinear Regression: A Practical Guide to Curve Fitting, Oxford University Press, Oxford, UK, 2004.

[18] G. Férey, C. Mellot-Draznieks, C. Serre et al., "A chromium terephthalate-based solid with unusually large pore volumes and surface area," Science, vol. 309, no. 5743, pp. 2040-2042, 2005.

[19] W. J. Weber and J. C. Morris, "Kinetics of adsorption on carbon from solution," Proceedings of the American Society of Civil Engineers/Journal of the Sanitary Engineering Division, vol. 89, pp. 31-59, 1963.

[20] M. A. Al-Ghouti, M. A. M. Khraisheh, M. N. M. Ahmad, and S. Allen, "Adsorption behaviour of methylene blue onto Jordanian diatomite: a kinetic study," Journal of Hazardous Materials, vol. 165, no. 1-3, pp. 589-598, 2009.

[21] V. Vadivelan and K. V. Kumar, "Equilibrium, kinetics, mechanism, and process design for the sorption of methylene blue onto rice husk," Journal of Colloid and Interface Science, vol. 286, no. 1, pp. 90-100, 2005.

[22] M. F. Sawalha, J. R. Peralta-Videa, J. Romero-González, and J. L. Gardea-Torresdey, "Biosorption of Cd(II), $\mathrm{Cr}(\mathrm{III})$, and $\mathrm{Cr}$ (VI) by saltbush (Atriplex canescens) biomass: thermodynamic and isotherm studies," Journal of Colloid and Interface Science, vol. 300, no. 1, pp. 100-104, 2006.

[23] R. R. Sheha and A. A. El-Zahhar, "Synthesis of some ferromagnetic composite resins and their metal removal characteristics in aqueous solutions," Journal of Hazardous Materials, vol. 150, no. 3, pp. 795-803, 2008.

[24] I. Langmuir, "The constitution and fundamental properties of solids and liquids," Journal of the American Chemical Society, vol. 38, no. 11, pp. 2221-2295, 1916.

[25] H. M. F. Freundlich, "Over the adsorption in solution," Journal of Physical Chemistry, vol. 57, pp. 385-471, 1915.

[26] G. D. Halsey, "The role of surface heterogeneity in adsorption," Advances in Catalysis, vol. 4, pp. 259-269, 1952.

[27] O. Redlich and D. L. Peterson, "A useful adsorption isotherm," Journal of Physical Chemistry, vol. 63, no. 6, pp. 10-24, 1959.

[28] R. Sips, "On the structure of a catalyst surface," Journal of Chemical Physics, vol. 16, no. 5, pp. 490-495, 1948. 
[29] J. Toth, "State equations of the solid gas interface layer," Acta Chimica Hungarica, vol. 69, pp. 311-317, 1971.

[30] G. F. Malash and M. I. El-Khaiary, "Piecewise linear regression: a statistical method for the analysis of experimental adsorption data by the intraparticle-diffusion models," Chemical Engineering Journal, vol. 163, no. 2010, pp. 256-263, 2010.

[31] T. Loiseau and G. Férey, "Crystalline oxyfluorinated openframework compounds: silicates, metal phosphates, metal fluorides and metal-organic frameworks (MOF)," Journal of Fluorine Chemistry, vol. 128, no. 4, pp. 413-422, 2007.

[32] N. Mohammadi, H. Khani, V. K. Gupta, E. Amereh, and S. Agarwal, "Adsorption process of methyl orange dye onto mesoporous carbon material-kinetic and thermodynamic studies," Journal of Colloid and Interface Science, vol. 362, no. 2, pp. 457-462, 2011.

[33] X. Peng, D. Huang, T. Odoom-Wubah, D. Fu, J. Huang, and Q. Qin, "Adsorption of anionic and cationic dyes on ferromagnetic ordered mesoporous carbon from aqueous solution: Equilibrium, thermodynamic and kinetics," Journal of Colloid and Interface Science, vol. 430, pp. 272-282, 2014.

[34] S. J. Allen, L. J. Whitten, M. Murray, O. Duggan, and P. Brown, "The adsorption of pollutants by peat, lignite and activated chars," Journal of Chemical Technology and Biotechnology, vol. 68, no. 4, pp. 442-452, 1997.

[35] M. Korczak and J. Kurbiel, "New mineral-carbon sorbent: Mechanism and effectiveness of sorption," Water Research, vol. 23, no. 8, pp. 937-946, 1989.

[36] Z. Hasan, J. Jeon, and S. H. Jhung, "Adsorptive removal of naproxen and clofibric acid from water using metal-organic frameworks," Journal of Hazardous Materials, vol. 209-210, pp. 151-157, 2012.

[37] S. Lin, Z. Song, G. Che et al., "Adsorption behavior of metal-organic frameworks for methylene blue from aqueous solution," Microporous and Mesoporous Materials, vol. 193, pp. 27-34, 2014.

[38] C.-K. Lee, K.-S. Low, and L.-C. Chung, "Removal of some organic dyes by hexane-extracted spent bleaching earth," Journal of Chemical Technology and Biotechnology, vol. 69, no. 1, pp. 93-99, 1997.

[39] E. I. Unuabonah, K. O. Adebowale, and B. I. Olu-Owolabi, "Kinetic and thermodynamic studies of the adsorption of lead (II) ions onto phosphate-modified kaolinite clay," Journal Hazardous Materials, vol. 144, pp. 386-395, 2007.

[40] A. Kumar, B. Prasad, and I. M. Mishra, "Adsorptive removal of acrylonitrile by commercial grade activated carbon: Kinetics, equilibrium and thermodynamics," Journal of Hazardous Materials, vol. 152, no. 2, pp. 589-600, 2008.

[41] M. I. El-Khaiary and G. F. Malash, "Common data analysis errors in batch adsorption studies," Hydrometallurgy, vol. 105, no. 3-4, pp. 314-320, 2011.

[42] A. Günay, E. Arslankaya, and I. Tosun, "Lead removal from aqueous solution by natural and pretreated clinoptilolite: adsorption equilibrium and kinetics," Journal of Hazardous Materials, vol. 146, no. 1-2, pp. 362-371, 2007.

[43] K. V. Kumar and S. Sivanesan, "Pseudo-second order kinetic models for safranin onto rice husk: Comparison of linear and non-linear regression analysis," Process Biochemistry, vol. 41, no. 5, pp. 1198-1202, 2006.

[44] H. Akaike, "A new look at the statistical model dentification," IEEE Transactions on Automatic Control, vol. 19, no. 6, pp. 716-723, 1974. 

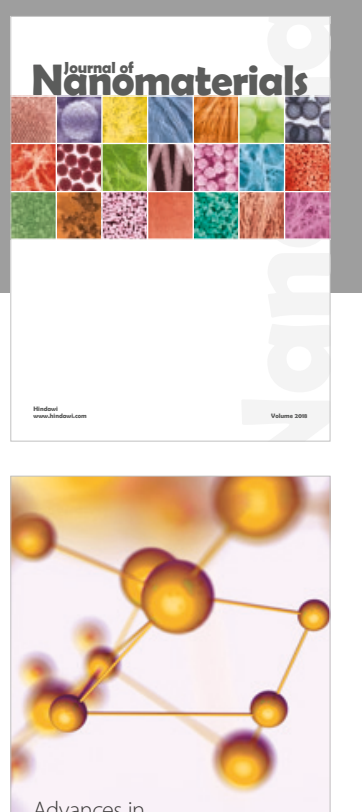

Physical Chemistry
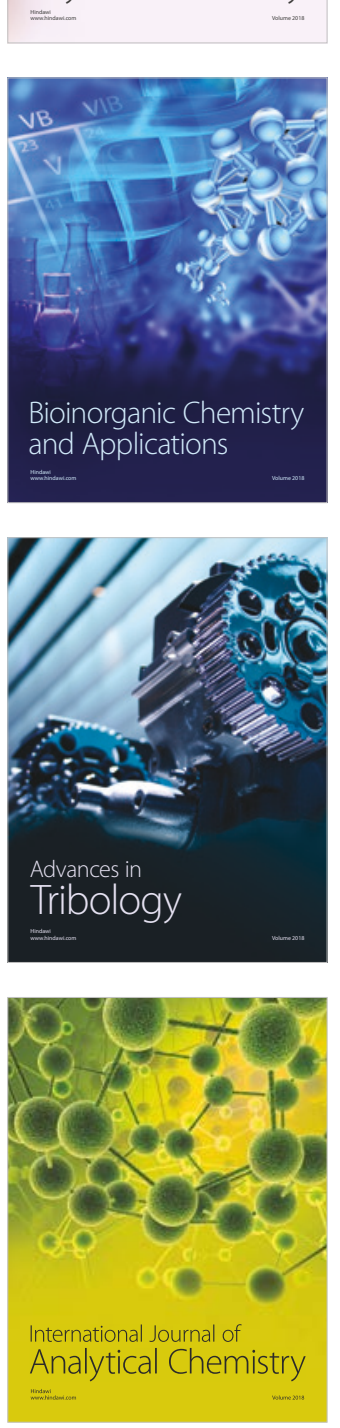

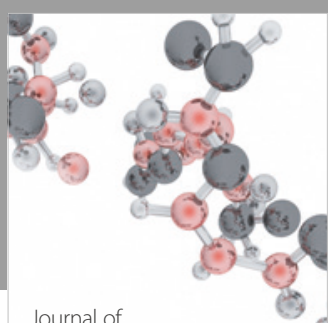

Analytical Methods

in Chemistry

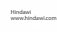

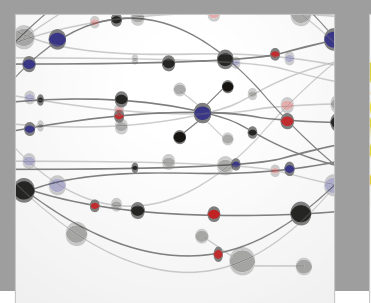

The Scientific World Journal

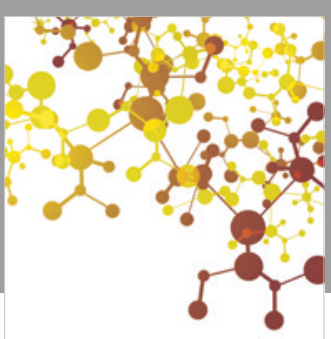

Journal of

Applied Chemistry
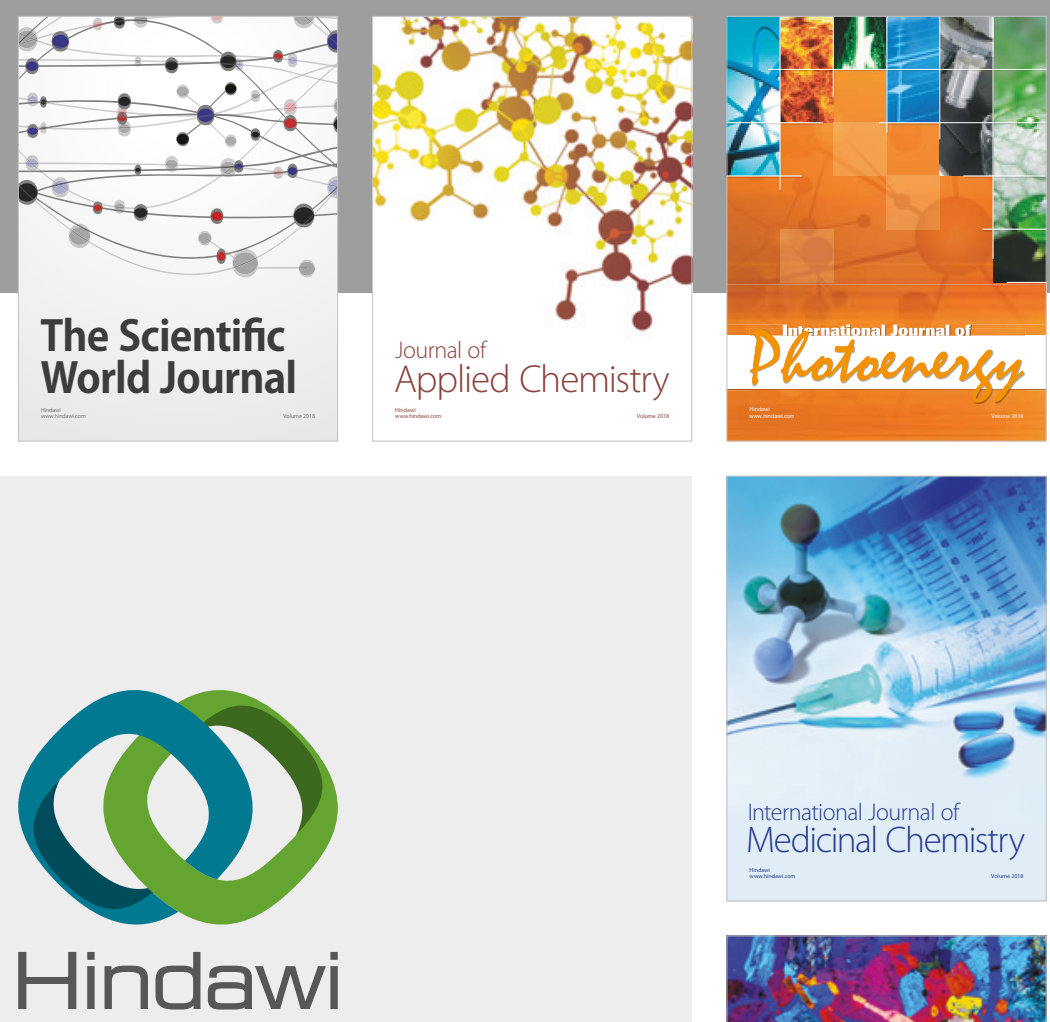

Submit your manuscripts at

www.hindawi.com
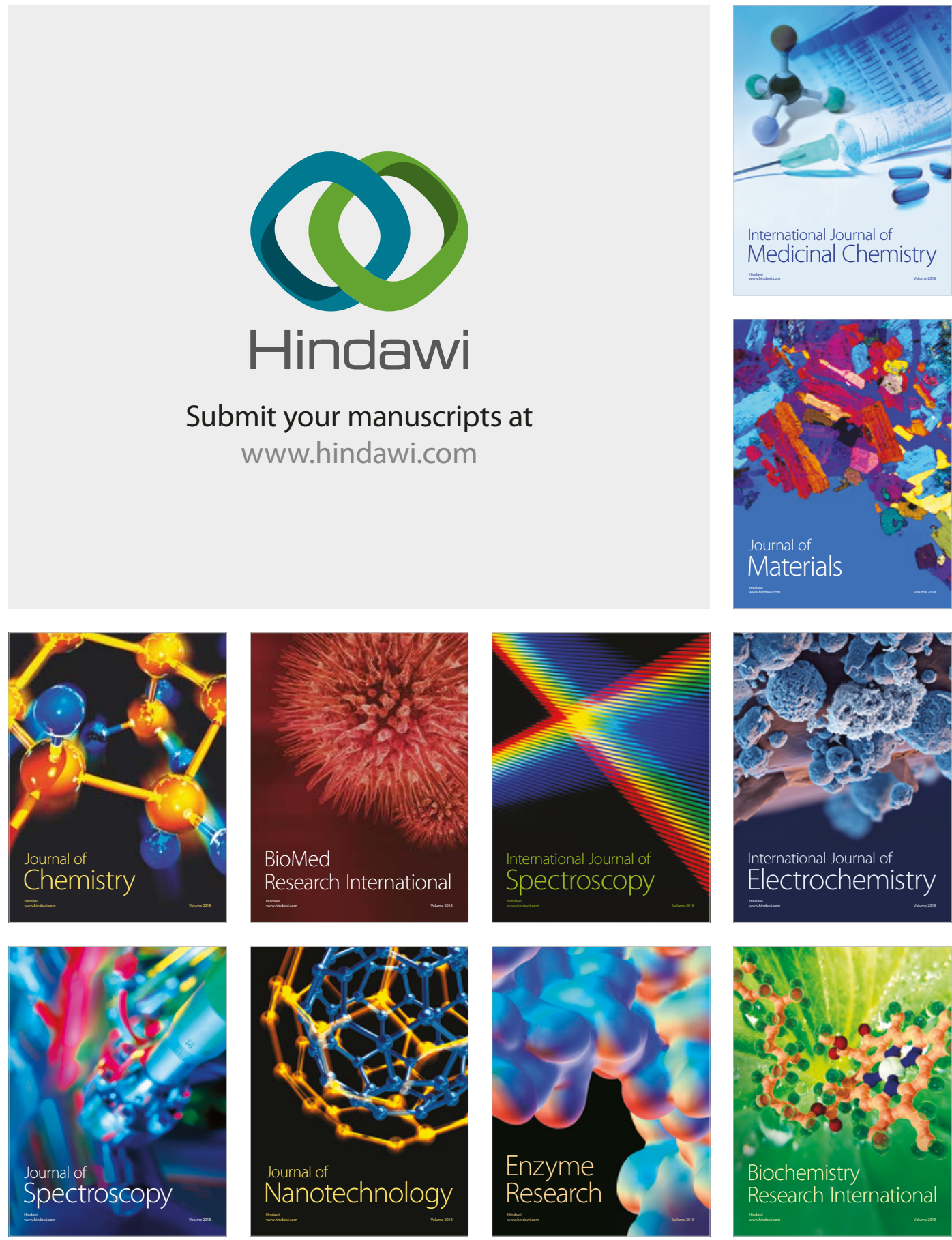
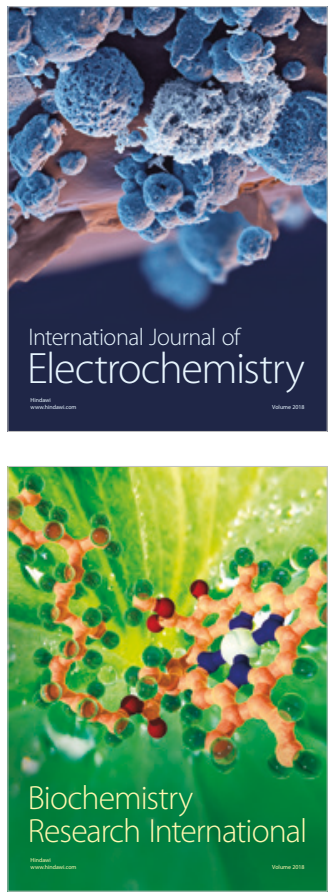